\title{
REVIEW ARTICLE OPEN Molecular mechanisms underpinning sarcomas and implications for current and future therapy
}

\author{
Victoria Damerell (iD) ${ }^{1}$ Michael S. Pepper (iD ${ }^{2}$ and Sharon Prince iD $^{1}$
}

\begin{abstract}
Sarcomas are complex mesenchymal neoplasms with a poor prognosis. Their clinical management is highly challenging due to their heterogeneity and insensitivity to current treatments. Although there have been advances in understanding specific genomic alterations and genetic mutations driving sarcomagenesis, the underlying molecular mechanisms, which are likely to be unique for each sarcoma subtype, are not fully understood. This is in part due to a lack of consensus on the cells of origin, but there is now mounting evidence that they originate from mesenchymal stromal/stem cells (MSCs). To identify novel treatment strategies for sarcomas, research in recent years has adopted a mechanism-based search for molecular markers for targeted therapy which has included recapitulating sarcomagenesis using in vitro and in vivo MSC models. This review provides a comprehensive up to date overview of the molecular mechanisms that underpin sarcomagenesis, the contribution of MSCs to modelling sarcomagenesis in vivo, as well as novel topics such as the role of epithelial-to-mesenchymal-transition (EMT)/mesenchymal-to-epithelial-transition (MET) plasticity, exosomes, and microRNAs in sarcomagenesis. It also reviews current therapeutic options including ongoing preclinical and clinical studies for targeted sarcoma therapy and discusses new therapeutic avenues such as targeting recently identified molecular pathways and key transcription factors.
\end{abstract}

Signal Transduction and Targeted Therapy (2021)6:246

; https://doi.org/10.1038/s41392-021-00647-8

\section{INTRODUCTION}

Sarcomas are a heterogeneous group of neoplasms derived from tissues of the mesenchyme such as bone, cartilage, muscle, and other connective tissues. Their heterogeneity is highlighted by the identification of over 100 different sarcoma subtypes which vary in pathology, clinical presentation, molecular characteristics, and response to therapy. ${ }^{1}$ Based on histopathological criteria and tissue type of primary manifestation, $80 \%$ of sarcomas are categorized as soft tissue sarcomas (STS), $15 \%$ as bone sarcomas, and $5 \%$ as gastro-intestinal stromal tumors (also known as GISTs) (Fig. 1). ${ }^{2,3}$ While relatively rare, sarcomas are often fatal and because they are of the most aggressive childhood cancers they are responsible for the loss of a significant number of years of life. ${ }^{4}$ Globally, the incidence of STS is around 3-4/100,000 persons per year which accounts for $1 \%$ of all adult solid malignant tumors and $>20 \%$ of all pediatric cancers. ${ }^{4,5}$ The prevalence of sarcomas may however be underestimated since those developing in parenchymatous organs are more often attributed to the organs affected rather than the surrounding connective or supporting tissue. ${ }^{6}$

The clinical management of sarcomas is highly challenging due to misdiagnosis because they are difficult to differentiate from other malignancies, late diagnosis due to the absence of symptoms, as well as their heterogeneity, aggressive nature, and resistance to current treatment options. Indeed, data published in the National Sarcoma Survey 2020, collected by Sarcoma UK in collaboration with Quality Health, reported that nearly a quarter (23\%) of patients had started treatment for another disease before being diagnosed with sarcoma. ${ }^{7}$ Furthermore, Raut et al. reported discordant histopathological diagnoses in up to $25 \%$ of sarcomas, of which over half had clinical significance and impact on treatment. ${ }^{8}$ In addition, the absence of symptoms and clinical presentation can result in late referrals to sarcoma specialists which delays diagnosis. ${ }^{9-11}$ Due to the heterogeneity of these tumors, response to conventional treatments such as surgery, radiation, and chemotherapy (Fig. 2) also varies and cannot be translated between different sarcoma subtypes. To date, the only promising curative treatment for localized sarcoma is surgery in combination with pre- or post-operative therapies. ${ }^{12}$ Metastatic sarcomas respond poorly to radiation and chemotherapy which is particularly problematic because one-third of patients develop metastases and about $20 \%$ of sarcomas recur. ${ }^{13}$ Furthermore, the 5 -year survival rate for localized STS is about $50 \%$ and $<10 \%$ for metastatic STS. ${ }^{14,15}$ While a proposed molecular targeted approach to treatment has gained traction, the molecular mechanisms that drive the sarcoma cells of origin to a transformed phenotype remain to be elucidated. This review, therefore, focuses on the key molecular mechanisms identified to be associated with sarcomagenesis and their potential as novel targets for sarcoma therapy.

\section{MOLECULAR MECHANISMS AND GENOMIC ALTERATIONS}

Sarcomagenesis is driven by fusion oncoproteins and/or mutations and amplifications that result in activation of oncogenes or loss-of-function of tumor suppressors, leading to unrestrained cell proliferation, invasion, and metastasis. At a genetic level, the karyotype of $15-20 \%$ of sarcomas is classified as simple while the

\footnotetext{
${ }^{1}$ Division of Cell Biology, Department of Human Biology, Faculty of Health Sciences, University of Cape Town, Observatory, Cape Town, South Africa and ${ }^{2}$ Institute for Cellular and Molecular Medicine, Department of Immunology, SAMRC Extramural Unit for Stem Research and Therapy, Faculty of Health Sciences, University of Pretoria, Pretoria, South Africa Correspondence: Sharon Prince (sharon.prince@uct.ac.za)
}

Received: 24 November 2020 Revised: 18 April 2021 Accepted: 18 May 2021

Published online: 30 June 2021 


\section{SOFT TISSUE (STS) AND BONE SARCOMAS}

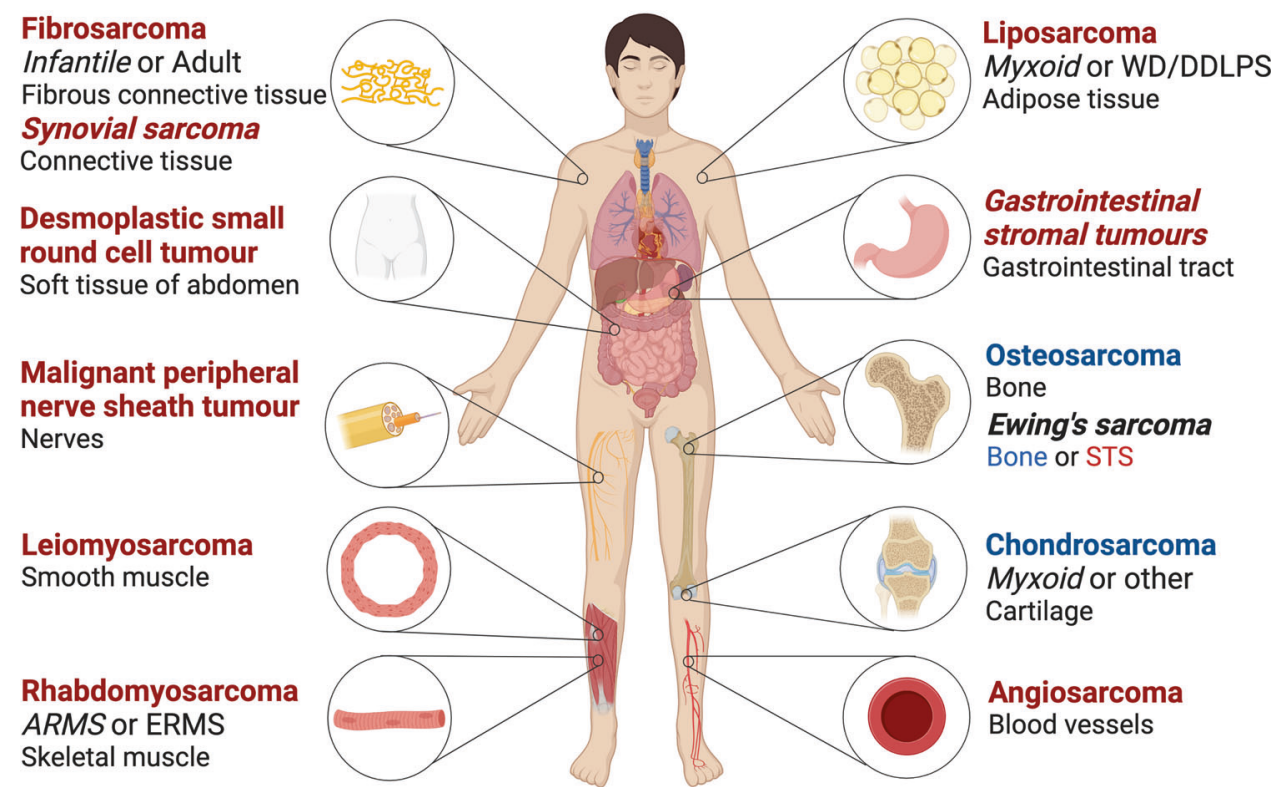

Fig. 1 Schematic representation of the most frequently occurring soft tissue (STS) (red) and bone (blue) sarcomas and affected tissues. Sarcomas with a simple karyotype are referred to in italics. ARMS alveolar rhabdomyosarcoma, ERMS embryonal rhabdomyosarcoma, WD/ DDLPS well-differentiated/dedifferentiated liposarcoma

\section{Conventional Sarcoma Treatment}

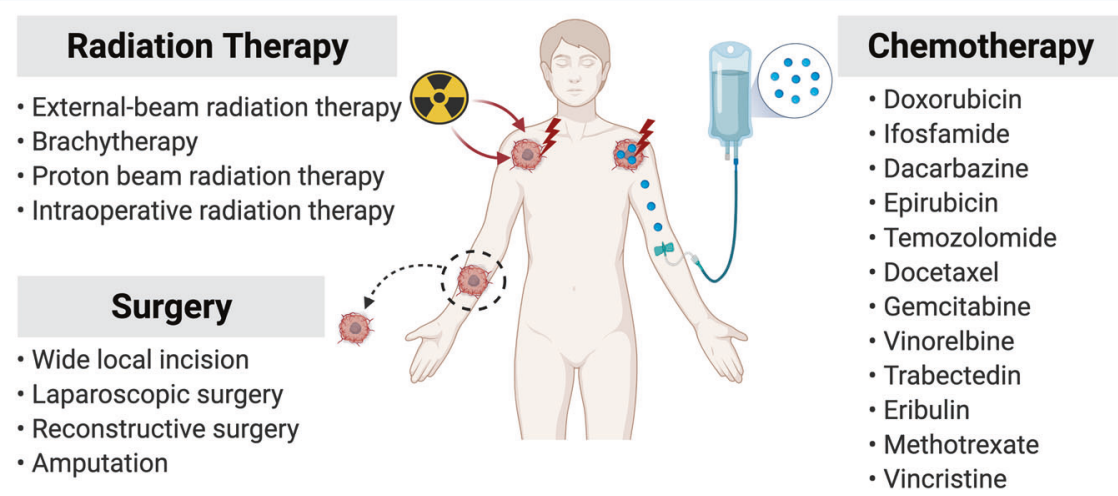

Fig. 2 Schematic illustration of conventional sarcoma treatment approaches

remaining is classified as complex. Sarcomas with simple karyotypes are defined by chromosomal translocations which lead to oncogenic fusion proteins which play a central role in their pathogenesis (Table 1). ${ }^{16}$ Sarcomas with complex karyotypes are associated with genetic or chromosomal abnormalities, such as losses, gains, and amplifications, as well as point mutations (Table 2). ${ }^{17-19}$ The rest of this section will review the genetic alterations most frequently associated with simple and complex karyotypes.

Alterations in cell cycle regulators

The mammalian cell cycle is comprised of four distinct phases, namely $G_{1}$ (cells prepare for DNA replication or decide to go into quiescence $\left(G_{0}\right)$ ), $S$ (DNA synthesis), $G_{2}$ (cells prepare for mitosis), and $M$ (mitosis) (Fig. 3). The transition from one phase to another is orchestrated by cyclin-dependent kinases (CDKs) which associate with their regulatory subunits, known as cyclins. When activated, cyclin-CDK complexes phosphorylate substrates that provide the forward impetus through the cell cycle and their inhibition by CDKIs triggers a 'checkpoint' that halts the cell cycle. $^{20}$ In mammals there are two classes of CDKIs, CIP/KIP $\left(\mathrm{p} 21^{\mathrm{CIP} 1}, \mathrm{p} 27^{\mathrm{KIP} 1}\right.$, and $\left.\mathrm{p} 57^{\mathrm{KIP} 2}\right)$ and INK4/ARF (p15 $5^{\mathrm{INK} 4 \mathrm{~b}}, \mathrm{p} 16^{\text {INK4a }}$, p18 ${ }^{\mathrm{INK} 4 \mathrm{c}}$, and $\mathrm{p} 14^{\mathrm{ARF}}$ ) which differ in their mechanism of action and specificity. ${ }^{21}$ Alternative splicing of the CDKN2A locus gives rise to $\mathrm{p} 16^{\mathrm{INK} 4 \mathrm{a}}$ and $\mathrm{p} 14^{\mathrm{ARF}}$ and $\mathrm{p} 16^{\mathrm{INK} 4 \mathrm{a}}$ blocks $\mathrm{G}_{1} / \mathrm{S}$ transition by interacting with CDK4/6 and inhibiting their association with type D-cyclins. ${ }^{22}$ This impedes CDK4/6-cyclin-D from phosphorylating retinoblastoma (RB) protein, and when hypo-phosphorylated, RB prevents entry into $\mathrm{S}$ phase by sequestering E2F transcription factors (TFs) and thereby inhibiting transcription of $S$ phase genes. ${ }^{23}$ Loss of $\mathrm{p} 16^{\mathrm{INK} 4 \mathrm{a}}$ consequently leads to unregulated phosphorylation of $\mathrm{RB}$, activation of $\mathrm{E} 2 \mathrm{~F}$ and its target genes as well as the transition from $G_{1}$ into $S$ phase. Under conditions of 
Table 1. Chromosomal changes observed in a selection of sarcomas with simple karyotype

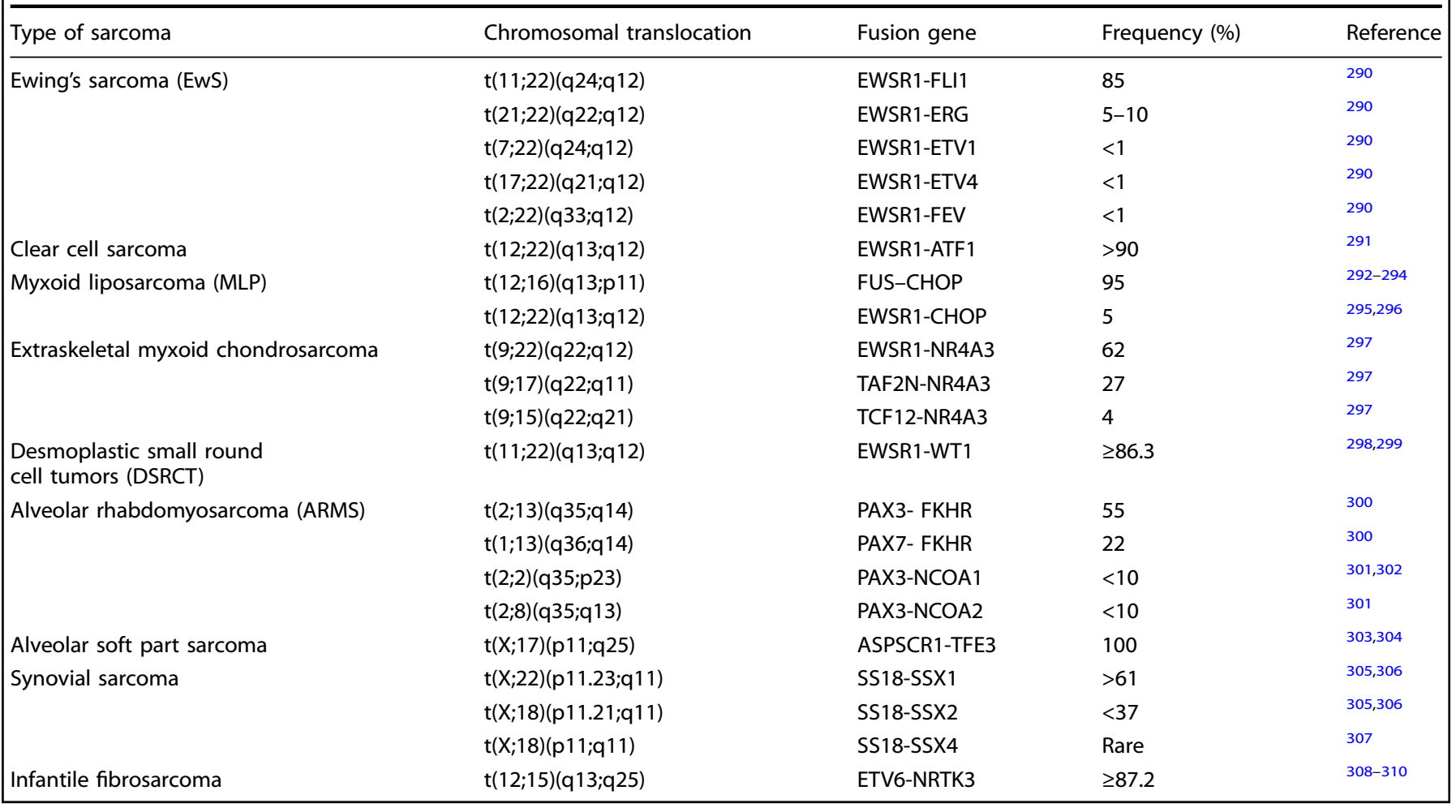

cellular stress, $\mathrm{p} 14^{\mathrm{ARF}}$ sequesters the ubiquitin E3 ligase, mouse double minute 2 homolog (MDM2), that would ordinarily target p53 for proteasomal degradation. ${ }^{24}$ The consequence of this is the stabilization and increase of p53 levels and the transcriptional activation of p53 targets including CDKIs such as p21 ${ }^{\mathrm{CIP} 1}$. This results in cell cycle arrests which can be followed by senescence and/or cell death by for example apoptosis. ${ }^{25}$ The p14 ${ }^{\text {ARF }}$-MDM2-p53 pathway thus plays a critical tumor suppressor role.

Clinicogenomic profiling of almost 8000 STS patients demonstrated that genetic alterations including loss of DNA copy number and point mutations frequently occur in $R B 1$ (22\%) and CDKN2A (22\%) with the latter significantly correlating with poor prognosis. ${ }^{26}$ Importantly, loss of the CDKN2A locus disrupts the p16 ${ }^{\text {INK4a }}$-RB and p14 ${ }^{\mathrm{ARF}}-\mathrm{p} 53$ tumor suppressor signaling which results in hyperactivation of CDKs and uncontrolled cell cycle progression. Somatic TP53 mutations, amplifications of MDM2, and loss-of-function mutations in $p 14^{A R F}$ have also been observed in a range of sarcomas and are linked with enhanced cell proliferation and survival, metastatic potential, chemotherapy resistance and poor overall patient survival. ${ }^{26-29}$ Furthermore, phosphatase and tensin homolog (PTEN) blocks AKT activation and consequently phosphorylation and translocation of MDM2 to the nucleus, and thus blocks p53 degradation. ${ }^{30}$ A multi-platform profiling of 2539 STS and bone sarcomas revealed loss of PTEN in $38.6 \%$ of sarcomas, most commonly in LMS, ARMS, osteosarcoma, chordoma, and epithelioid sarcoma. ${ }^{31}$

The upregulation of positive cell-cycle regulators such as the TFs c-Myc, Forkhead Box F (FoxF1/FoxF2), and T-box transcription factor 3 (TBX3) has also been implicated in sarcomagenesis. Indeed, c-Myc is upregulated in a number of sarcomas including leiomyosarcoma, osteosarcoma, chondrosarcoma, synovial sarcoma, ARMS and EwS. ${ }^{32-39}$ Myc is a basic helix-loop-helix zipper transcription factor that regulates its target genes by binding to a conserved E-box DNA sequence CACGTG. ${ }^{40}$ It mainly exerts its effect on the cell cycle by transcriptionally activating cyclins and $C D K s$ or by repressing $p 15^{I N K 4 b}, p 21^{C I P 1}$, and $p 27^{K I P 1} \cdot{ }^{41-44}$ In rhabdomyosarcoma cells, c-Myc, FoxF1 and FoxF2 are each capable of directly repressing $p 21^{C I P 1}$ to promote proliferation and anti-apoptosis. ${ }^{45,46}$ In the case of Ewing's sarcoma, p21 ${ }^{C I P 1}$ is directly repressed by EWS-FLI1 fusion protein. ${ }^{47}$ TBX3 belongs to the developmentally important T-box transcription factor family and is overexpressed in a broad range of sarcoma subtypes which are largely dependent on it for the cancer phenotype. ${ }^{48}$ During Sphase, c-Myc transcriptionally activates TBX3 in chondrosarcoma and rhabdomyosarcoma cells and TBX3 represses $p 21^{C I P 1}$ to confer a proliferative advantage to these cells. ${ }^{49,50} \mathrm{~A}$ summary of cell cycle proteins involved in sarcomagenesis is illustrated in Fig. 3.

Alterations in growth factor and pro-survival signaling pathways Most sarcoma subtypes are associated with mutations that result in constitutive activation of pro-survival and growth-factor signaling pathways (Fig. 4). These include the platelet-derived growth factor (PDGF), insulin-like growth factor (IGF), epidermal growth factor (EGF), c-KIT and c-MET pathways which promote tumorigenesis by activating downstream Ras/Raf/MAPK and/or $\mathrm{PI3K} / \mathrm{PTEN} / \mathrm{AKT} / \mathrm{mTOR}$ pathways. ${ }^{31,51-59} \mathrm{PTEN}$ negatively regulates the $\mathrm{PI} 3 \mathrm{~K} / \mathrm{AKT} / \mathrm{mTOR}$ pathway and, as mentioned earlier, is lost in $38.6 \%$ of sarcomas leading to the aberrant activation of this pathway. ${ }^{31,60}$ Furthermore, downstream of the PI3K/AKT pathway, the protein kinase mTOR plays a major role in translating proteins for cell-cycle progression, cell growth, and survival, and has therefore become an attractive target for sarcoma therapy. ${ }^{61}$ In addition, TBX3 is an important mediator of rhabdomyosarcomagenesis downstream of the PI3K/PTEN/AKT/mTOR pathway. Indeed, phosphorylation by AKT1 stabilizes TBX3, and TBX3 promotes rhabdomyosarcoma proliferation, anchorageindependent growth and tumor formation. ${ }^{50}$ Furthermore, aberrant stimulation of the WNT, Notch and Hedgehog-GLI signaling pathways promotes proliferation, invasion, and metastasis of a 
Damerell et al.

Table 2. Frequent genetic alterations observed in sarcomas with complex karyotypes

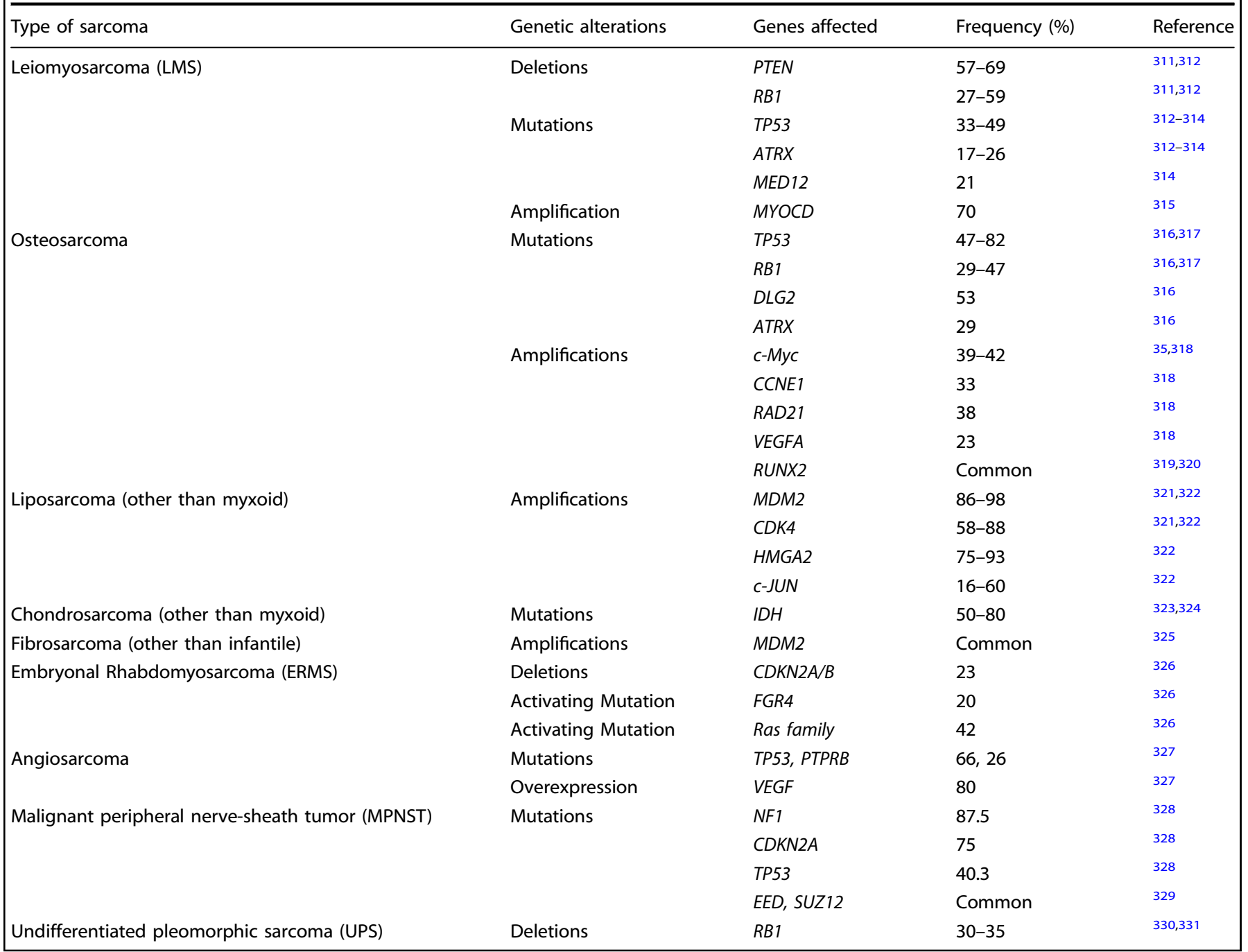

range of sarcoma subtypes. ${ }^{62-68}$ Finally, the Hippo pathway prevents uncontrolled proliferation by phosphorylating and preventing nuclear translocation of the TFS YAP and TAZ, and molecular aberrations within this pathway have been linked to sarcomagenesis. ${ }^{69}$ For example, YAP and TAZ are aberrantly activated in $66 \%$ of sarcoma cell lines and $50 \%$ of sarcoma patientderived tissues and this correlated with increased proliferation, anchorage-independent growth and tumor progression. ${ }^{70}$

Alterations in angiogenic signaling pathways

Angiogenesis which is the formation of new blood vessels, is required for tumor cell growth, invasion and metastasis. ${ }^{71}$ The vascular endothelial growth factor (VEGF) family members VEGF-A, $-B,-C,-D$ and placental growth factor (PGLF) are master regulators of angiogenesis and mediate their biological effects via the surface receptors VEGFR1, VEGFR2, and VEGFR3. ${ }^{72}$ Activation of the VEGF/ VEGFR pathway triggers endothelial cell growth and neovascularization from pre-existing vessels; it is therefore not surprising that this pathway is often activated during oncogenesis. ${ }^{73}$ Importantly, upregulation of VEGFs and VEGFRs has been observed in at least $25 \%$ of sarcomas, and is linked to advanced tumor stage and poor prognosis. ${ }^{74-76}$ Furthermore, analysis of 115 STS patients revealed significantly higher levels of VEGF tissue concentration in patients with local recurrence and metastasis, which correlated with poor overall survival. ${ }^{77}$ In addition, immunohistochemical analysis revealed that VEGFR1, VEGFR2 and VEGFR3 were expressed at high levels in $61 \%, 11 \%$ and $64 \%$ of 275 STS tumors, respectively, and this was significantly associated with higher tumor grade. ${ }^{78}$ Feng et al. also found moderate and high VEGF expression in 37\% and $40.7 \%$ of synovial sarcoma patients respectively, which was associated with histological grade, cancer staging and metastasis. ${ }^{75}$ Similarly, a correlation between VEGF expression, tumor stage and patient survival has been reported for bone sarcomas. For example, in osteosarcoma patients, those with VEGF-positive tumors had a significantly higher incidence of pulmonary metastases and worse overall survival compared to those with VEGF-negative tumors. ${ }^{79}$ Finally, overexpression of VEGF in STS cell lines led to accelerated growth and formation of highly vascular tumors, pulmonary metastases and chemoresistance in experimental models in vivo. ${ }^{80}$

Alterations in factors promoting invasion and metastasis Epithelial-to-mesenchymal transition (EMT)/mesenchymal-to-epithelial transition (MET) plasticity in sarcomas. Tumor metastasis involves tumor cells from the primary site invading neighboring tissues, intravasation and transport of tumor cells through the blood or lymphatic systems, and extravasation and tumor growth at secondary sites. In carcinomas, this is facilitated by tumor cells undergoing an EMT which reduces their adhesion properties and 


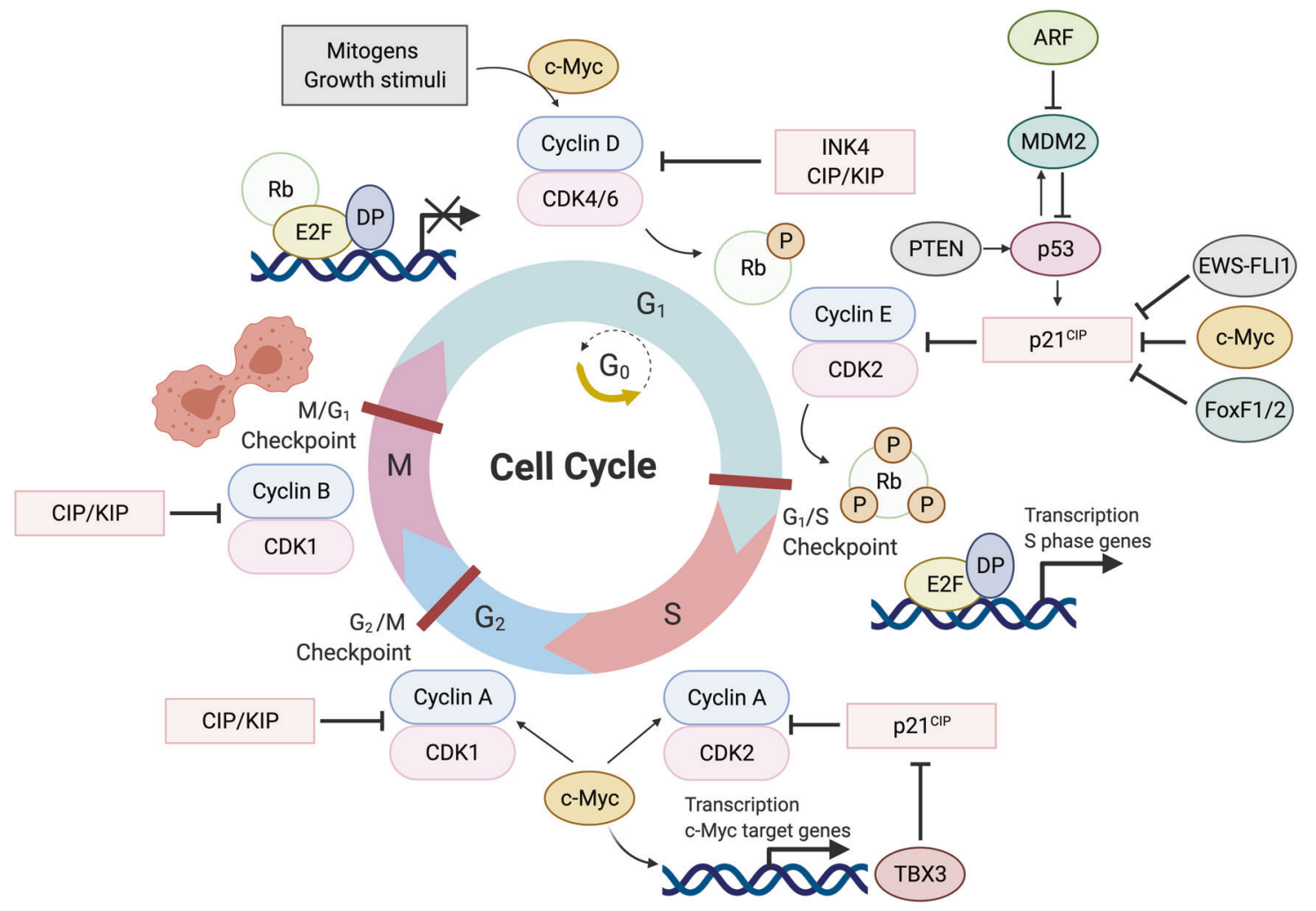

Fig. 3 Schematic illustration of the mammalian cell cycle and proteins involved in sarcomagenesis

enhances their migratory and invasive abilities. Once they reach their destination, they undergo a reverse process termed MET to establish metastases. ${ }^{81}$ EMT is characterized by the downregulation of the epithelial cell-cell adhesion molecule E-cadherin and the upregulation of the TFs Twist-related protein 1 (TWIST-1), Zinc finger E-box-binding homeobox (ZEB)1/2, SLUG, SNAIL, and the EMT inducer transforming growth factor $\beta$ (TGF- $\beta$ ). ${ }^{82,83}$

Unlike carcinomas, EMT processes in sarcomas are largely unknown and seem paradoxical since they are, by definition, mesenchymal in nature. However, based on recent evidence, Sannino et al. propose that sarcoma cells may reside in a metastable state, and depending on cellular context, can either differentiate towards an epithelial or more mesenchymal phenotype. $^{84}$ This EMT/MET plasticity has been linked to an aggressive phenotype, ${ }^{84}$ and several EMT/MET TFs have been shown to play a role in sarcomagenesis. For example, downstream of the PI3K/ AKT/mTOR and MAPK/ERK pathways, SLUG and SNAIL promote EMT-related processes in chondro- and rhabdomyosarcoma cells respectively. ${ }^{85-87}$ On the other hand, downregulation of SNAIL due to an epigenetic switch in chondrosarcoma cells resulted in MET which corresponded with expression of epithelial markers, Ecadherin, maspin, desmocollin 3 , and $14-3-3 \sigma^{88}$ Similarly, in synovial sarcomas, TGF- $\beta$ may drive phenotypic switching by upregulating TWIST-1, SNAIL and SLUG which promote cell migration and invasion. ${ }^{89,90}$ The SYT-SSX1 and SYT-SSX2 fusion proteins can reverse the mesenchymal phenotype in synovial sarcoma cells through binding to SNAIL and SLUG respectively, thereby preventing them from repressing E-cadherin. ${ }^{91}$ In rhabdomyosarcoma and osteosarcoma cells, miR-200 inhibits ZEB1 and thereby induces E-cadherin and co-expression of miR200 and grainyhead-like transcription factor 2 (GRHL2) results in a multiplicative increase in E-cadherin and morphological changes consistent with MET. ${ }^{92}$ More is known about EMT/MET processes in osteosarcoma cells since several factors including TGF- $\beta$,
microRNAs (miRs), BMP-2 and Interleukin-33 (IL-33) have been identified to regulate these processes. For example, TGF- $\beta$ promotes EMT by upregulating SNAIL and subsequently downregulating E-cadherin ${ }^{93}$ and miR-23a and miR-130a induce EMT in osteosarcoma cells by directly downregulating PTEN. ${ }^{94,95}$ In addition, BMP-2 upregulated ZEB2 and activated Wnt/ $\beta$-catenin signalling in these osteosarcoma cells. This promoted EMT and invasiveness through the inhibition of E-cadherin and increased levels of the mesenchymal markers SNAIL, N-cadherin and vimentin. ${ }^{96,97}$ When the $\mathrm{Wnt} / \mathrm{\beta}$-catenin pathway was blocked with the dominant negative soluble low-density lipoprotein receptorrelated protein 5 (sLRP5), EMT was reversed as seen by upregulated levels of E-cadherin and downregulated levels of SLUG, TWIST and matrix metalloproteinases (MMPs). ${ }^{98}$ A recent study demonstrated that IL-33 may promote EMT by downregulating $\mathrm{E}$-cadherin and upregulating MMP-9 and N-cadherin. ${ }^{99}$ Importantly, the upregulation of MMPs does not only occur in osteosarcoma, but has also been reported in several STS where they promote cell invasion and metastasis. ${ }^{100-102}$ Taken together, the above findings indicate that EMT/MET plasticity plays a key role during sarcomagenesis and the factors involved are summarized in Fig. 5.

microRNAs. Short non-coding microRNAs have been shown to either inhibit or promote sarcoma metastasis, mainly through the modulation of EMT TFs and MMPs. For example, miR-708-5p, miR126, and miR-130a impair osteosarcoma EMT, migration, invasion, and metastasis by directly inhibiting ZEB1 expression and miR708-5p also downregulates MMP-2, MMP-7 and MMP-9. ${ }^{103-105}$ In a similar manner, overexpression of miR-30d repressed EwS cell migration and invasion by inhibiting PI3K/AKT/mTOR and MAPK/ ERK pathways as well as MMP-2 and MMP-9 levels. ${ }^{106}$ Recently, miR-200b-3p, miR-30c-1-3P, and miR-363-3P were reported to inhibit GIST invasion via direct downregulation of SNAI2. ${ }^{107}$ In 
Damerell et al.

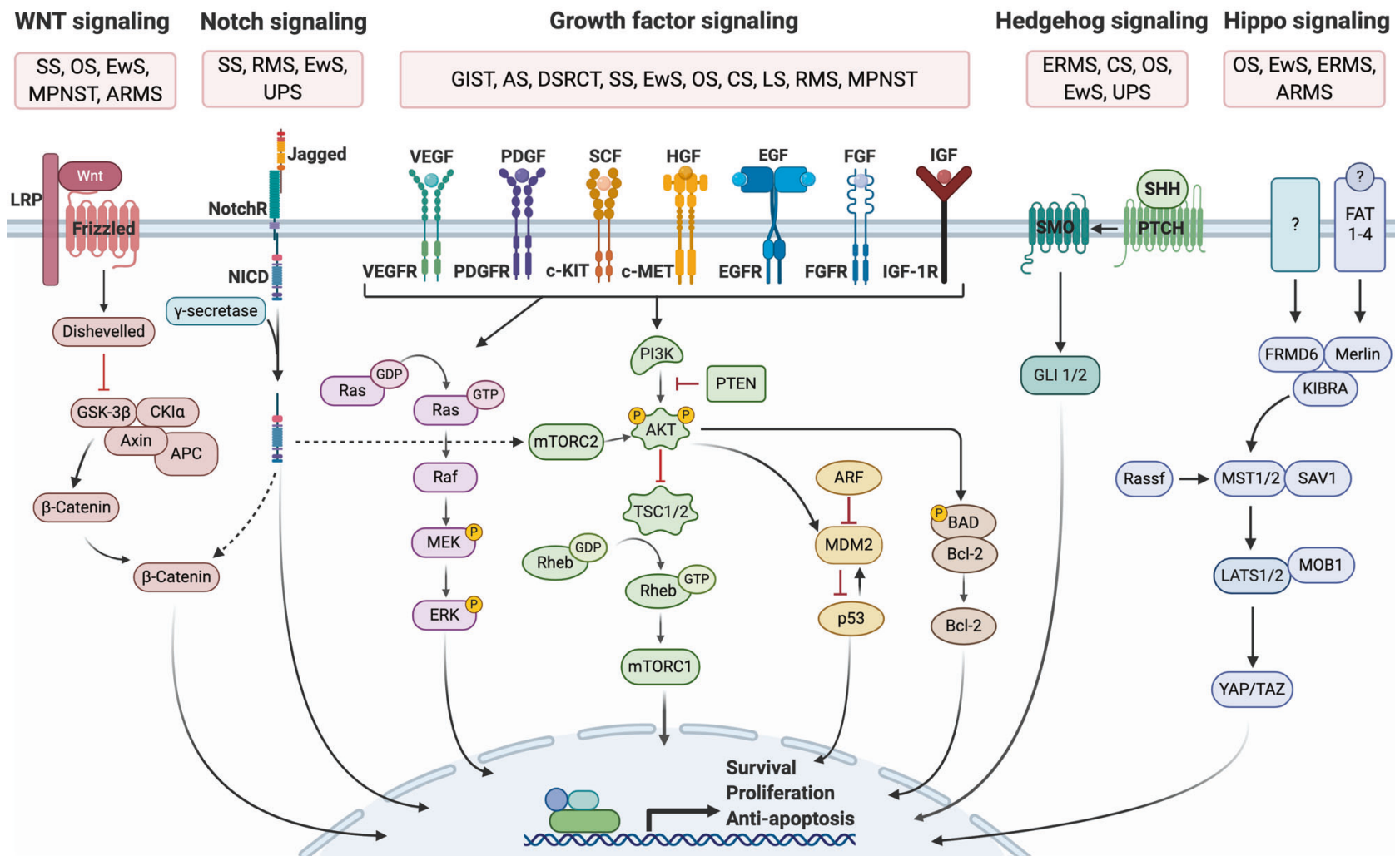

Fig. 4 Schematic illustration of key signaling pathways underpinning sarcomagenesis. Wnt signaling: $\mathrm{SS}^{271} \mathrm{OS}^{272,273} \mathrm{EwS}^{27,}{ }^{62,274} \mathrm{MPNST},{ }^{275-277}$ ARMS, ${ }^{278}$ Notch signaling: SS, ${ }^{279}$ RMS, $^{279}$ EWS, $^{62}$ UPS $_{1}^{280}$; Growth-factor signaling: GIST, ${ }^{53-55} \mathrm{DSRCT}^{51} \mathrm{AS}^{31,281} \mathrm{SS}^{58}$ LS $^{31} \mathrm{CS}^{31} \mathrm{OS}^{52} \mathrm{EWS}^{62,282}$ $\mathrm{RMS}^{57,283}$ MPNST, ${ }^{284}$; Hedgehog signaling: UPS, ${ }^{280} \mathrm{OS}^{63}, \mathrm{ERMS}^{64} \mathrm{CS}^{65}{ }^{65} \mathrm{EWS}^{62}$; Hippo signaling: OS, ${ }^{138,285} \mathrm{EWS}^{286,287} \mathrm{ERMS}^{288}$ ARMS. $^{289}$ Abbreviations: ARMS alveolar rhabdomyosarcoma, AS angiosarcoma, CS chondrosarcoma, DSRCT desmoplastic small round cell tumors, ERMS embryonal rhabdomyosarcoma, EwS Ewing's sarcoma, GIST gastro-intestinal stromal tumor, LMS leiomyosarcoma, LS liposarcoma, MPNST malignant peripheral nerve sheath tumor, OS osteosarcoma, SS synovial sarcoma, UPS undifferentiated pleomorphic sarcoma

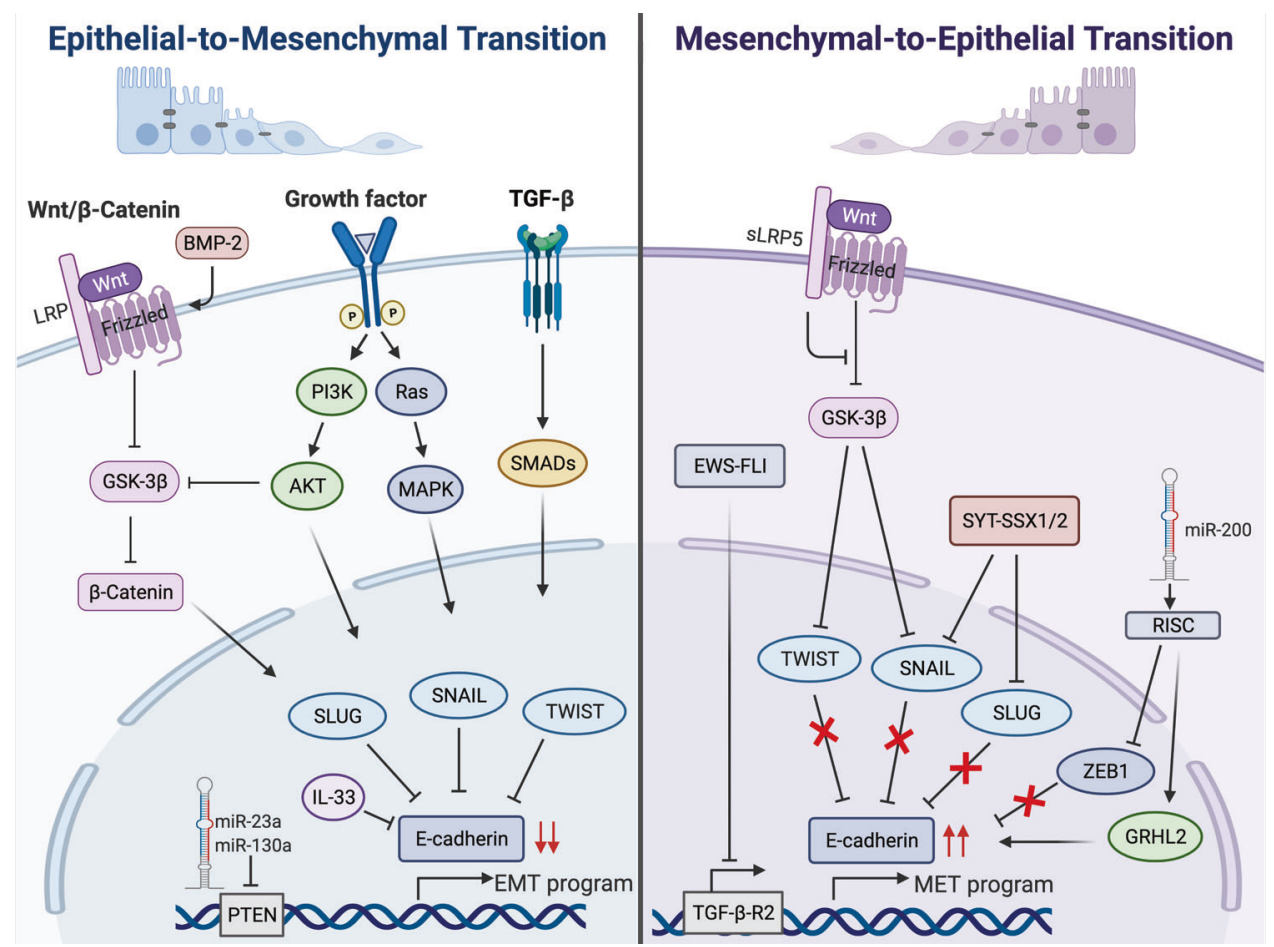

Fig. 5 Factors promoting epithelial-to-mesenchymal transition (EMT) and mesenchymal-to-epithelial transition (MET) in sarcomagenesis 


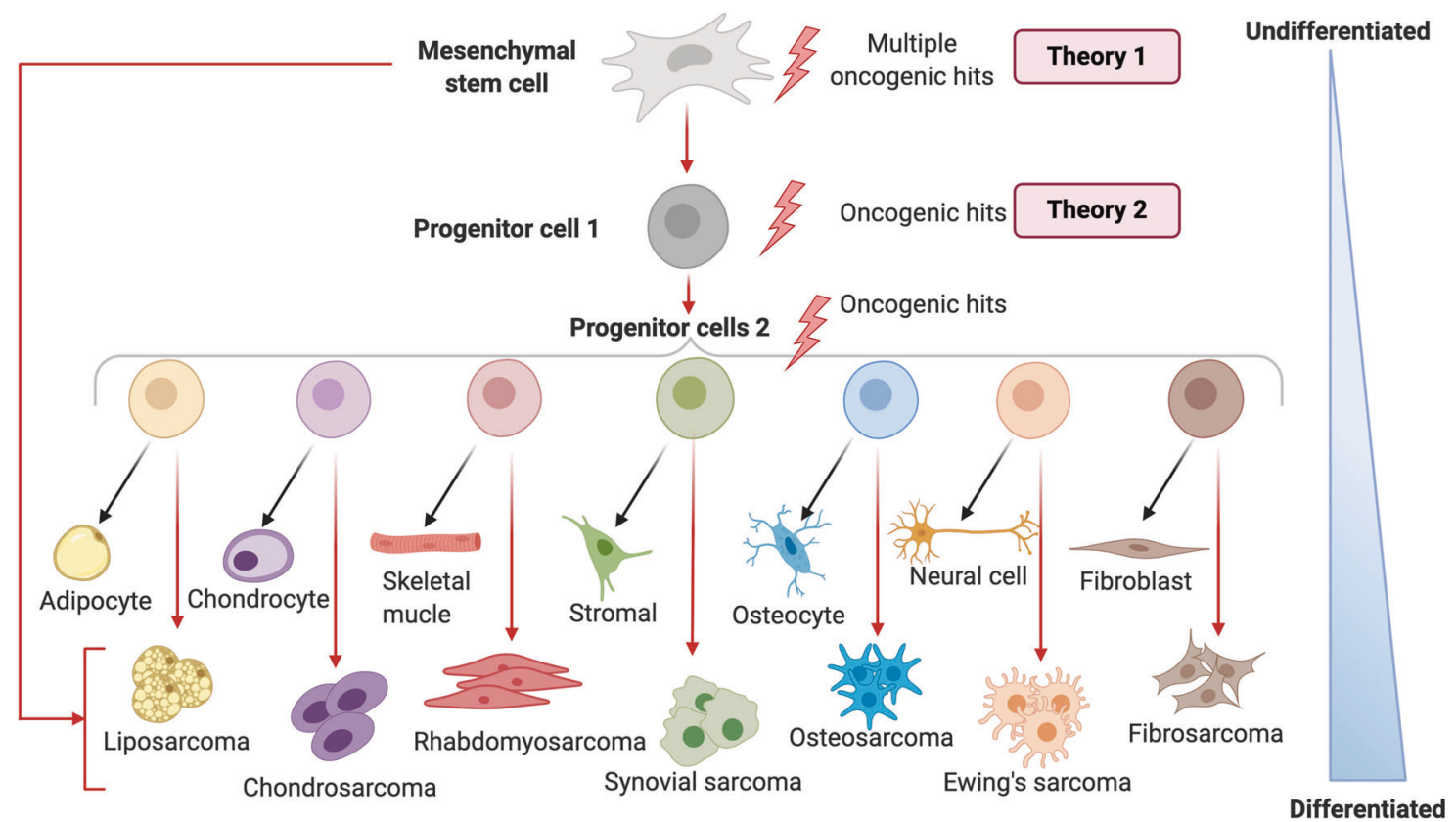

Fig. 6 Mesenchymal stromal/stem cell (MSC) differentiation and sarcomagenesis. Schematic representation of malignant transformation of MSCs into several sarcoma subtypes driven by several oncogenic hits (red arrows). During normal development, MSCs mature through different stages (progenitor cells) towards a final differentiated cell such as an adipocyte, chondrocyte, osteocyte, skeletal myocyte, fibroblast, neural, and stromal cell. Theory 1 suggests that oncogenic hits occur in primitive MSCs; theory 2 suggests that oncogenic hits occur in progenitor cells which drives their malignant transformation. The two theories are not mutually exclusive but they feed into a model where sequential genomic alterations in a primitive MSC and/or its progenitor cells result in an accumulation of oncogenic hits followed by malignant transformation

contrast, miR-182 promotes STS metastasis by downregulating tissue inhibitor of matrix metalloproteinase-1 (TIMP-1) followed by upregulation of its downstream targets and key mediators of cell invasion, MMP-2 and MMP-9. ${ }^{108}$ MicroRNA-135b also upregulated MMP-2 in myxoid liposarcoma which resulted in increased cell invasion in vitro and metastasis in vivo. ${ }^{109}$ Furthermore, miR-181a is overexpressed in high-grade chondrosarcoma and promotes angiogenesis and metastasis by upregulating VEGF and MMP-1. ${ }^{110}$ Taken together, the above studies show that microRNAs are important for sarcoma EMT/MET plasticity and metastasis, and are thus potentially attractive targets for treatment.

Extracellular vesicles. Exosomes are extracellular vesicles secreted by several cell types that are important for cell-to-cell communication. Their components include proteins, mRNA, miRNA, and DNA, and have been implicated in the regulation of tumorigenesis and metastasis. ${ }^{11}$ For example, osteosarcoma-derived exosomes were reported to be enriched for proteins implicated in tumor progression, migration, angiogenesis, and metastasis. ${ }^{112}$ Furthermore, gene ontology analysis showed an enrichment for miRNAs associated with tumorigenesis and metastasis in metastatic osteosarcoma-derived exosomes. ${ }^{12}$ In addition, miR-25-3p and miR-92a-3p were shown to be secreted by liposarcoma cells though exosomes and induced interleukin- 6 secretion from tumor-associated macrophages, which promoted liposarcoma cell proliferation, invasion, and metastasis. ${ }^{113}$ Since cancer-derived exosomes contribute to metastasis, their disruption may constitute a novel therapeutic strategy. ${ }^{114}$ Indeed, a preclinical study has shown that targeting breast-cancer-derived exosomes with human-specific anti-CD9 or anti-CD63 antibodies significantly reduced metastasis in vivo. ${ }^{115}$ More studies are required to elucidate the exact molecular mechanisms of exosome-related metastasis in sarcomas, and how to target these for treatment.

Exosomes may also represent a useful tool for targeted anticancer drug delivery. For example, miR-143 downregulates MMP-
13 to suppress osteosarcoma cell invasion and metastasis, and exosome-mediated delivery of miR-143 to osteosarcoma cells significantly reduced their migration. ${ }^{116,117}$ In addition, in a murine sarcoma model, exosome-mediated delivery of siTGF- $\beta 1$-inhibited TGF- $\beta$ signaling, tumor growth, and lung metastases. ${ }^{118}$ More investigations are needed to evaluate the potential of exosomes as delivery systems for targeted therapy in sarcomas.

Together, the above sections provide evidence that alterations in several factors and signaling pathways that regulate the cell cycle, angiogenesis, invasion, and metastasis, co-operate to promote sarcomagenesis. Understanding these has been important for modelling sarcomagenesis in MSCs.

\section{MESENCHYMAL STEM CELLS AS THE PUTATIVE ORIGIN OF SARCOMAS}

The cells which give rise to sarcomas still remain unclear but recent evidence suggests that MSCs may be sarcoma-initiating cells. ${ }^{119,120}$ MSCs are multipotent stromal/stem cells that are found in most human adult tissues and they give rise to differentiated cell types including adipocytes, chondrocytes, skeletal myoblasts, osteocytes, neural cells and fibroblasts (Fig. 6). Sarcomas are histopathologically classified based on cell-lineage of differentiation and the normal tissue type that they resemble, and two theories have been proposed as to how they arise (Fig. 6). Theory 1 suggests that sarcomas arise from primitive MSCs, which acquire mutations that direct tumorigenesis and theory 2 proposes that progenitor cells acquire mutations at different stages of differentiation which leads to a block in terminal differentiation and subsequent tumor development (Fig. 6). ${ }^{119}$

Modelling sarcomagenesis using MSCs

Several studies have reported that following the introduction of oncogenic hits, primary MSCs can transform into sarcomas. Indeed, the overexpression of FUS-CHOP combined with loss of p53 in 
murine MSCs induced liposarcoma-like tumors. ${ }^{121}$ Furthermore, cMyc overexpression was sufficient to transform murine bone marrow (BM)-MSCs into osteosarcoma in vivo and when combined with loss of the Ink4a/Arf locus, the process was substantially accelerated. ${ }^{122}$ The authors further showed that these osteosarcoma cells consisted of two subpopulations with one showing altered tri-lineage differentiation potential and resistance to conventional anti-cancer drugs. It would however appear that forced expression of a single oncogene in human MSCs (hMSCs) is not sufficient to induce sarcoma development. For example, the expression of EWS-FLI1 alone, was not capable of transforming hMSCs into EwS and expression of FUS-CHOP was only capable of transforming hMSCs into myxoid liposarcoma in the presence of several other oncogenic hits including p53 and pRB deficiency, hTERT overexpression, c-Myc stabilization, and $\mathrm{H}_{-} \mathrm{RAS}^{\mathrm{V} 12}$ mutation. ${ }^{123,124} \mathrm{~A}$ recent study also showed that overexpression of c-Myc alone enhanced the proliferation of human adipose-derived MSCs (ASCs) and altered their trilineage differentiation potential in vitro but it had no effect on their tumor forming ability in vivo. ${ }^{125}$ A combination of c-Myc overexpression and RB knockdown in hMSCs could however transform them into osteosarcoma. ${ }^{126}$ Another study reported that $3 \mathrm{H}$ transformed hMSCs (overexpression of hTERT, p53, and pRB degradation) manipulated to overexpress c-JUN and c-JUN/c-FOS developed into fibroblastic and pleomorphic osteoblastic osteosarcomas, respectively. ${ }^{127}$ Combined overexpression of the liposarcoma diagnostic markers, MDM2 and CDK4, increased human $2 \mathrm{H}$ transformed BM-MSCs (overexpression of hTERT, p53 degradation) proliferation, migration, and inhibited adipogenic differentiation potential in vitro. However, MDM2 and CDK4 overexpression in these MSCs only led to tumor growth in vivo and the formation of dedifferentiated liposarcoma when combined with three additional oncogenic hits (c-Myc stabilization, RB inactivation, and overexpression of $\left.\mathrm{H}-\mathrm{RAS}^{\mathrm{V} 12}\right) .{ }^{128}$ In contrast to the above findings, Vishnubalaji et al. provided evidence that overexpression of a single oncogene LIN28B in human BM-MSCs resulted in fibromyxoid sarcoma-like tumors in vivo with increased angiogenesis. ${ }^{129}$ The above studies provide overwhelming evidence that at least two oncogenic hits are required to transform hMSCs into sarcomas in vivo.

Despite the evidence from in vitro and in vivo models suggesting that MSCs are the cells of origin of sarcomas, additional studies are necessary to elucidate the mechanisms of MSC transformation into individual sarcoma subtypes.

Modelling sarcomagenesis using mesenchymal progenitor cells The possibility that cells of the osteoblastic lineage (preosteoblasts, mature osteoblasts, or osteocytes) may be the cells of origin of osteosarcoma has been widely debated. ${ }^{130-132}$ Indeed, p53 is a critical regulator of osteogenesis and studies using conditional and transgenic mouse models showed that inactivation of TP53 in osteogenic progenitors led to the formation of highly metastatic osteosarcomas which was potentiated by loss of $R B .^{133-136}$ Furthermore, constitutive Notch activation in committed murine osteoblasts was sufficient to induce osteosarcoma-like tumors, and when combined with loss of TP53, osteosarcoma development was substantially accelerated. ${ }^{137}$ Similarly, upregula-

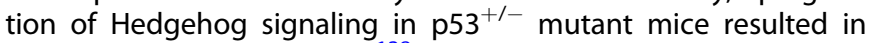
osteosarcoma development. ${ }^{138}$ Collectively, these studies provide evidence that the loss of p53 is critical for the initiation of osteosarcoma which is consistent with the majority of osteosarcomas exhibiting TP53 mutations/deletions. Interestingly, Rubio et al. showed that loss of TP53 and RB in osteogenic progenitors derived from murine BM-MSCs, but not ASCs, resulted in the formation of metastatic osteosarcoma. ${ }^{139}$ Additionally, leiomyosarcoma-like tumors were promoted in TP53 and RB null undifferentiated BM-MSCs or ASCs. ${ }^{139}$ Together these observations suggest that not only is a certain level of osteogenic differentiation required for osteosarcoma development but that the source of the cells of the osteogenic lineage is also important.
Yang et al. recently provided additional evidence to support this. They showed that consecutive introduction of the oncogenes hTERT, SV40 large T antigen and H-Ras transformed human preosteoblasts into osteosarcoma but transformed hMSCs into spindle cell sarcoma. ${ }^{140}$ It is worth noting that osteosarcoma generated from cells of the osteocalcin-lineage i.e. mature osteoblasts, were less osteoblastic compared to osteosarcoma generated from pre-osteoblasts, suggesting that the final differentiation status of osteosarcoma does not necessarily reflect that of their cells of origin. ${ }^{141}$ The final differentiation state of osteosarcomas was proposed to be dependent on silencing of epigenetic regulators such as DNA methyltransferases during osteosarcomagenesis. Furthermore, results from several in vivo studies suggest that osteosarcomas generated from committed progenitor cells are not able to de-differentiate or transdifferentiate into other sarcoma types. ${ }^{142}$ There is also evidence that other sarcomas such as synovial sarcoma, EwS, and myxoid liposarcoma can result from the introduction of the fusion oncoproteins SYT-SSX2, EWS-FLI1, or FUS-CHOP into murine primary mesenchymal progenitors, respectively. ${ }^{143-146}$ Future studies should evaluate whether these oncogenic hits are sufficient to transform human mesenchymal progenitor cells into different sarcoma subtypes.

While the above studies suggest that sarcomas, especially osteosarcomas, can arise from mesenchymal progenitor cells at different stages of differentiation, there is currently a lot more evidence to suggest that sarcomas arise from multiple genetic alterations occurring in primitive MSCs. This may however be due to more studies having been performed with primitive hMSCs and we can therefore not exclude the possibility that sarcomas may arise from either primitive hMSCs or hMSC-derived progenitor cells.

\section{MOLECULAR TARGETED THERAPY}

The standard treatment for localized sarcomas is surgery combined with neoadjuvant (pre-operative) or adjuvant (postoperative) therapies such as chemotherapy and radiation. ${ }^{147}$ Although patients with localized sarcomas have a high chance of complete recovery with surgery, when their tumors recur or metastasize the prognosis is dismal. This is particularly problematic as $10-20 \%$ of sarcomas recur and up to $50 \%$ of patients develop metastases. ${ }^{147,148}$ Chemotherapy is the standard form of treatment for metastatic sarcomas; however, the reported median overall survival is only 12 months and $<10 \%$ of patients have a 5 year overall survival rate. ${ }^{15,149,150}$ There is therefore clearly a need for more effective therapies as the traditional approaches have been mostly ineffective. Targeted therapies may overcome the current therapeutic limitations; however, most sarcoma subtypes have alterations in many signaling pathways and therefore effective therapy will probably need to target a range of pathways. In this section, we review the most relevant pathways that are currently targeted by commercially available drugs, as well as ongoing preclinical and clinical trials on potential novel targeted therapies (summarized in Fig. 7).

\section{TARGETING CELL CYCLE PROGRESSION}

Cell cycle inhibitors (CDKIs)

CDKls are being tested for the treatment of sarcomas as they can inhibit aberrant cell cycle activation. First generation CDKls such as flavopiridol (PubChem CID: 5287969) performed poorly in patients and were associated with toxicity, which is partly due to their lack of specificity. ${ }^{151}$ Second generation inhibitors such as dinaciclib (PubChem CID: 46926350) had more specificity for fewer CDKls and displayed less toxicity; however, their performance was disappointing in early phase clinical trials. ${ }^{151}$ The major problem with non-selective CDKIs is their inability to differentiate between normal and cancer cells. Therefore, efforts have focused on 


\section{Current Targeted Therapies for Sarcomas}

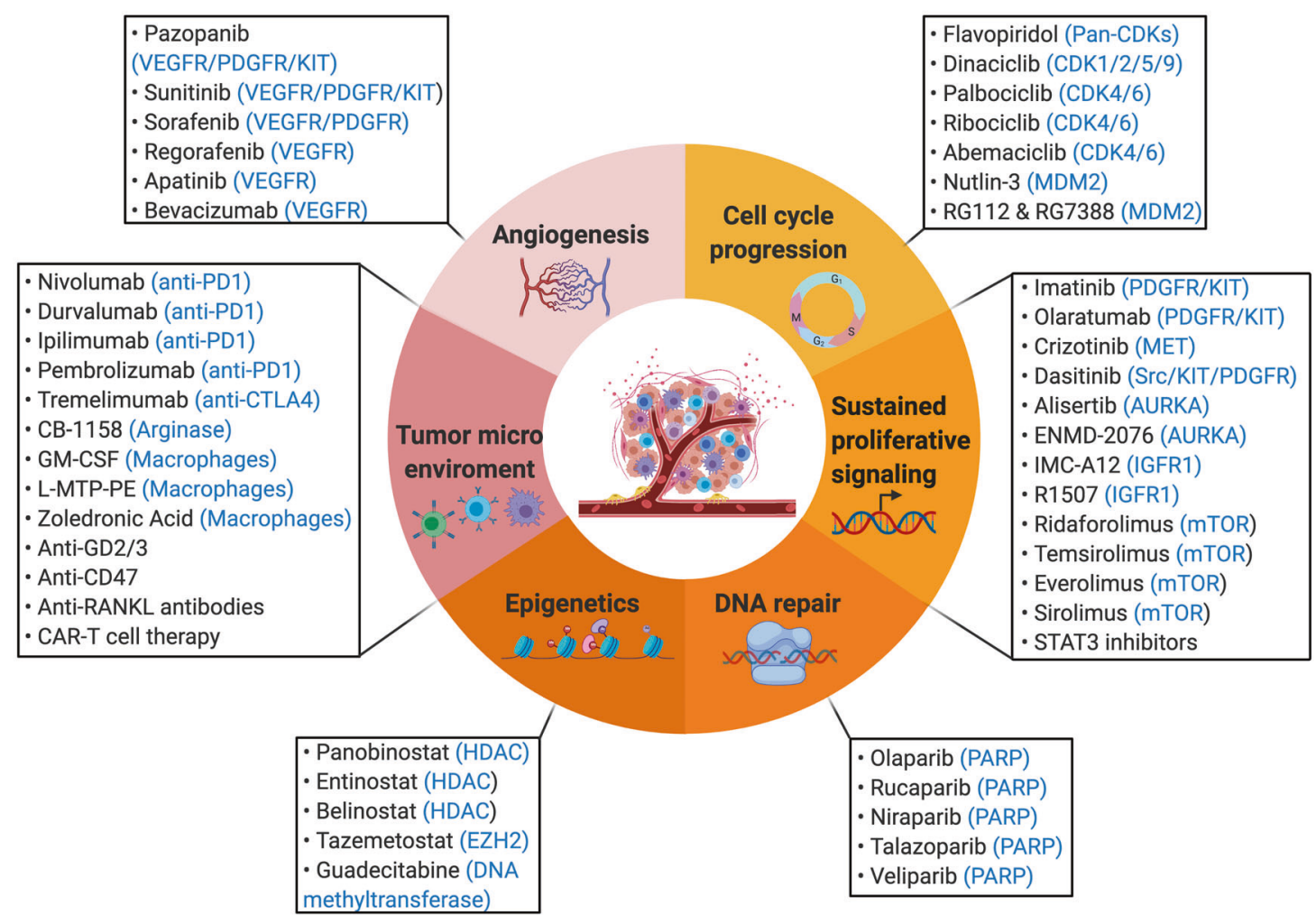

Fig. 7 Current targeted therapies for sarcomas. Illustration shows a selection of experimental and approved drugs and their respective targets (highlighted in blue) aimed to inhibit features of sarcomagenesis including cell cycle progression, sustained proliferative signaling, DNA repair, epigenetics, tumor microenvironment, and angiogenesis

developing single CDK-specific inhibitors that exhibit maximum antitumor effects with minimal toxic side effects. Currently, the most promising agents include the CDK4/6 inhibitors palbociclib (PubChem CID: 5330286), ribociclib (PubChem CID: 44631912), and abemaciclib (PubChem CID: 46220502). For example, CDK4 amplification is typical in over $90 \%$ of well-differentiated/dedifferentiated liposarcomas (WD/DDLPS), and palbociclib has demonstrated antitumor potential in preclinical studies and a phase II clinical trial of patients with advanced or metastatic WD/DDLPS and resulted in a more favorable progression-free survival (NCT01209598). ${ }^{151}$ Palbociclib may also be beneficial for osteosarcoma treatment since they frequently have disruptions in the pRB pathway, such as loss of p16 ${ }^{\text {INK4a }}$ and/or amplification of CDK4/6. ${ }^{152}$ Despite the promising preclinical and clinical data, limitations such as acquired drug resistance to CDK4/6 inhibitors are coming to light. ${ }^{153-155}$ In an attempt to overcome these challenges with CDK-monotherapy, ongoing clinical trials are mostly focusing on combination therapies (NCT04129151, NCT03709680, NCT02897375, NCT02784795, NCT03009201, NCT03114527, NCT02343172).

The ubiquitin E3 ligase MDM2 which is responsible for ubiquitinating and targeting p53 for degradation, is often amplified in sarcomas. ${ }^{156}$ This has prompted the development of MDM2 therapeutic inhibitors including nutlin-3 (PubChem CID: 216345) and RG7112 (PubChem CID: 57406853). ${ }^{25}$ Nutlin-3 was shown to repress tumor formation by inducing apoptosis in osteosarcoma xenografts by stimulating the p53 signaling pathway. ${ }^{157}$ Furthermore, RG7112 significantly reduced tumor growth in patients with MDM2-amplified liposarcoma in a phase I clinical trial. ${ }^{149}$ Liposarcomas frequently harbor amplifications of both MDM2 and CDK4, and therefore a combination therapy targeting both factors may have a synergistic effect and lead to a better treatment outcome. Indeed, a preclinical study by Laroche-Clary et al. found that compared to monotherapy, a combination of the MDM2 inhibitor RG7388 (PubChem CID: 53358942) with the CDK4/6 inhibitor palbociclib led to significantly reduced tumor growth in DDLPS xenografts and increased progression-free survival. ${ }^{158}$

\section{TARGETING GROWTH RECEPTORS AND PRO-SURVIVAL SIGNALING MOLECULES}

Tyrosine kinase inhibitors (TKIs)

TKIs represent a highly successful form of targeted therapy for sarcomas. For example, the c-KIT, PDGF, and VEGF receptors are currently being targeted in approved therapeutics. Eighty percent of GISTs harbor mutations in C-KIT and $10 \%$ harbor mutations in PDGFRa; this leads to constitutive ligand-independent activation of these receptors which promotes uncontrolled cell proliferation and anti-apoptosis. ${ }^{159}$ Molecular-targeted therapy has significantly improved the prognosis of GISTs which are intrinsically resistant to chemotherapy and radiation. Indeed, one of the first FDAapproved molecular targeted drugs is imatinib (PubChem CID: 5291), a TKI which inhibits both c-KIT and PDGFR. ${ }^{160}$ Imatinib has shown great efficacy for the treatment of GISTs and is currently used as the first line treatment for these tumors. ${ }^{161}$ A study on GISTs in the United States by Demetri et al. reported a $>50 \%$ response to imatinib in which the estimated 1-year overall survival was $88 \%{ }^{162}$ Long-term data confirmed the success of imatinib with a 5 -year overall survival of about $50 \% .{ }^{163}$ Based on these findings, the therapeutic use of imatinib has been extended to 
other sarcomas that contain c-KIT and PDGFR mutations. However, the response rates of other sarcomas have mostly been poor. ${ }^{164}$ Indeed, a phase II clinical trial which assessed the performance of imatinib on 22 metastatic or relapsed KIT- or PDGFR-positive sarcomas only showed partial response in a single patient. ${ }^{165}$ Therefore, there was no correlation between the response to imatinib and expression levels of PDGFR/KIT.

Pazopanib (PubChem CID: 10113978) is another TKI that targets VEGFR with high affinity and both C-KIT and PDGFR with lower affinity. ${ }^{166}$ Results from the PALETTE phase III clinical trial showed that pazopanib was beneficial in treatment-resistant metastatic sarcomas and improved progression-free survival by 3 months. ${ }^{167}$ While this led to its FDA-approval as a second-line treatment for advanced STS, treatment with pazopanib has been linked to side effects such as diarrhea, weight loss, nausea, fatigue, and hypertension. ${ }^{167}$ A recent phase II clinical trial (GISG-04/NOPASS) by the German Interdisciplinary Sarcoma Group assessed the effect of pazopanib as preoperative therapy in 21 STS patients; beneficial effects were only observed in a single patient. ${ }^{168}$

Sorafenib (PubChem CID: 216239) is a multi-TKI that inhibits VEGFR and PDGFR and results from phase II clinical trials indicated that it had moderate activity as a second-line therapy for metastatic STS. ${ }^{169-171}$ Furthermore, for patients with desmoid tumors, sorafenib significantly prolonged progression-free survival. ${ }^{172} \mathrm{~A}$ recent phase II clinical trial showed that a combination of sorafenib with the cytotoxic agent ifosfamide (PubChem CID: 3690) achieved significant clinical benefit in advanced STS patients. ${ }^{173}$ Another phase II clinical trial used sorafenib in combination with the cytotoxic agent dacarbazine (PubChem CID: 135398738) in leiomyosarcoma, synovial sarcoma, and MPNST patients; modest activity and a favorable disease-control rate were observed, although the combination also increased the potential for significant toxic side effects. ${ }^{174}$ Importantly, a pooled analysis of several clinical trials between 2009 and 2016, showed that treatment with pazopanib, sorafenib and sunitinib (PubChem CID: 5329102) was linked to significantly increased risk of toxicity and severe adverse side effects. ${ }^{175}$

Small molecule inhibitors that target TKs may be associated with less adverse side effects. For example, the small molecule inhibitor ZD6474 (PubChem CID: 3081361) targets TKs including VEGFR-2 and EGFR, and in preclinical osteosarcoma studies was shown to block cell proliferation and enhance cell cycle arrest and cell death by suppressing the PI3K/AKT and MAPK/ERK pathways. ${ }^{176}$ Furthermore, the combination of ZD6474 with the COX-2 inhibitor celecoxib (PubChem CID: 2662) resulted in an additive or synergistic anti-tumor effect in vitro and in vivo. ${ }^{176}$ To date, ZD6474 has not yet being tested in clinical trials for sarcoma treatment, but it significantly improved the progression-free survival for medullary thyroid cancer in a phase II clinical trial. ${ }^{177}$

Although the use of TKIs results in clinical efficacy in STS other than GISTs, one of the biggest challenges is the lack of validated predictive biomarkers for patients who are most likely to respond positively to TKI treatment. ${ }^{178}$ Furthermore, TKIs still have limited therapeutic application due to their side effects such as hypertension, arterial and venous thromboembolic events, and hand-foot skin reactions. ${ }^{179,180}$

IGFR inhibitors

Monoclonal antibodies that target IGFR-1, such as cixutumumab (IMC-A12) or R1507, showed modest clinical benefit for EwS, liposarcoma, osteosarcoma, rhabdomyosarcoma, and synovial sarcoma patients in phase II clinical trials. ${ }^{181,182}$ However, most patients who initially responded to therapy developed drug resistance and suffered from disease recurrence. ${ }^{183}$ Therefore, combination therapies are currently under investigation in many preclinical studies. For instance, a combination of inhibitors to IGFR and CDK4/6 profoundly repressed the PI3K/mTOR pathway and had a synergistic anti-tumor effect in vitro and in vivo in EwS. ${ }^{184}$

\section{mTOR inhibitors}

The mTOR inhibitor ridaforolimus (PubChem CID: 11520894), an analogue of rapamycin, has shown promising results for the treatment of several sarcomas. Results from a phase II clinical trial showed that ridaforolimus had clinical benefit and only mild to moderate adverse side effects for patients with metastatic or unresectable STS and bone sarcomas. ${ }^{185}$ In contrast, an international randomized phase III clinical trial demonstrated that second-line treatment with ridaforolimus delayed sarcoma progression to only a small extent. ${ }^{186}$ Furthermore, the placebo and ridaforolimus-treated groups had comparable overall survival rate and therefore the FDA rejected the approval application for ridaforolimus in 2012. Other inhibitors of mTOR namely everolimus (PubChem CID: 6442177), temsirolimus (PubChem CID: 6918289) and sirolimus (PubChem CID: 46835353) were assessed in single-agent clinical trials; however, results were mostly disappointing. ${ }^{149}$ Preclinical phase investigations are therefore currently under way for combination therapies. For example, cotreatment with ridaforolimus and palbociclib resulted in a synergistic anti-tumor effect in a range of sarcoma cell lines and in a murine fibrosarcoma model. ${ }^{187}$

\section{OTHER THERAPEUTIC AVENUES}

Inhibition of epigenetic regulators

Histone deacetylase inhibitors (HDACi) are powerful epigenetic regulators that affect tumor cells by interfering with cell growth, inducing apoptosis and inhibiting angiogenesis. ${ }^{188}$ Although preclinical studies have shown promising anti-cancer activity of the HDACi panobinostat (PubChem CID: 6918837), monotherapy in advanced STS did not show clinical benefit in phase II clinical trials; different combination therapies are therefore currently in development. $^{189,190}$ For example, HDAC inhibitors enhanced the anti-cancer effect of pazopanib against sarcoma cells, and this effect was even more pronounced in combination with the TK inhibitor, neratinib. ${ }^{191,192}$ Furthermore, results from a phase I clinical trial found panobinostat to increase the efficacy of the topoisomerase II inhibitor epirubicin (PubChem CID: 41867) and this led to clinical benefit and has the potential to reverse anthracycline resistance. ${ }^{193}$ Interestingly, tazemetostat (PubChem CID: 66558664), a lysine methyltransferase inhibitor of the histone modification enzyme enhancer of zeste homolog $2(E Z H 2)$, was approved by the FDA in 2020 as the first epigenetic therapy for solid tumors and is used to treat advanced or metastatic epithelioid sarcoma. ${ }^{194}$ EZH2 is upregulated in numerous sarcomas including synovial sarcoma, rhabdomyosarcoma, EwS, and MPNST, where it promotes tumorigenesis and cancer progression. ${ }^{195}$ Importantly, the inhibition of EZH2 in these sarcomas resulted in cell death and a reduction in tumor growth. Thus, EZH2 represents a potential therapeutic target in a range of sarcomas, and clinical studies should therefore investigate the effect of tazemetostat in other sarcoma subtypes. The treatment of ARMS and ERMS with the DNA methyltransferase inhibitor guadecitabine (PubChem CID: 135564655) also reduced cell growth, induced apoptosis and differentiation, and repressed ARMS tumor growth in vivo; this occurred by activating canonical Hippo signaling and downregulating YAP1, a known tumor promoter of RMS. ${ }^{196}$

Poly(ADP-ribose) polymerase (PARP) inhibitors

PARP enzymes are important players in the repair of DNA singlestrand breaks through the base-excision repair pathway, and their inhibition was found to potentiate the cytotoxic effect of DNAdamaging agents. ${ }^{197,198}$ Inhibitors of PARP (PARPi) represent a novel class of anti-cancer agents that are especially effective against cancers with DNA-repair defects where they induce 
synthetic lethality. ${ }^{199}$ Recently, PARP inhibitors have also been identified as promising agents for sarcoma treatment. ${ }^{200}$ Olaparib (PubChem CID: 23725625), an FDA-approved PARPi, is currently in Pediatric MATCH phase II trials for advanced, recurrent, and refractory STS and bone sarcomas resulting from defects in DNA damage repair genes (NCT03233204 and NCT03155620). Furthermore, multiple clinical trials are either underway or have investigated the performance of chemotherapy-PARPi combinations (NCT02044120, NCT01858168, NCT02116777, NCT03880019). Indeed, a Phase $\mathrm{lb}$ clinical trial assessed the combination of olaparib and the DNA alkylating agent trabectedin (PubChem CID: 108150) which are both known to cause accumulation of singlestrand and double-strand DNA breaks. Results showed manageable toxicity of the combination and encouraging anti-tumor activity in advanced STS and bone sarcoma patients (NCT02398058). 201,202 Perez et al. recently reported that a synergistic effect can be achieved when olaparib is combined with the DNA damaging agent doxorubicin (PubChem CID: 31703) in vitro and in sarcoma patient-derived xenograft (PDX) models. ${ }^{203}$ The authors further showed that this combination was most effective in tumors that expressed high levels of $\mathrm{pH} 2 \mathrm{AX}$ and MAP17. Furthermore, due to the radiosensitizing activities of PARPi, a phase lb study is currently investigating the effects of combining olaparib with concomitant radiotherapy to treat locally advanced/unresectable STS (NCT02787642). Taken together, PARPi in combination with DNA damaging agents/radiotherapy may be an effective treatment strategy for both STS and bone sarcomas.

\section{Immunotherapy}

The most popular immunotargets include programmed cell death protein (PD)-1 and its ligand PD-L1 as well as cytotoxic Tlymphocyte-associated protein (CTLA)-4. ${ }^{204}$ Clinical trials are currently investigating the potential of monoclonal antibodies $(\mathrm{mAB})$ against PD-L1 and CTLA-4 to treat DDLPS and pleiomorphic liposarcoma (NCT02500797 and NCT03114527). Other ongoing phase II clinical trials are investigating the effect of the PD-L1 inhibitor durvalumab in combination with pazopanib or tremelimumab (CTLA-4 inhibitor) to treat advanced STS (NCT03798106 and NCT02815995). However, pooled analysis of results from recent phase II clinical trials revealed that, as single agents or in combination therapy, PD-1/PD-L1 antagonists have limited activity in unselected STS. ${ }^{205}$ Whereas patients with undifferentiated pleomorphic sarcoma and alveolar soft part sarcoma showed the highest overall response and non-progression rate, leiomyosarcoma patients showed the lowest overall response and nonprogression rate. This suggests that the success of anti-PD1/PD-L1 treatment is largely dependent on specific sarcoma subtypes. Molgora et al. further demonstrated that the inhibition of TREM2, a pro-tumorigenic marker of tumor-associated macrophages, with an anti-TREM2 $\mathrm{mAB}$, substantially increased the performance of anti-PD-1 treatment in a sarcoma mouse model. ${ }^{206}$ This combination strategy is of particular interest since it effectively targets the immunosuppressive tumor microenvironment and enhances antitumor immune responses. The efficacy of monotherapy with a CTLA-4 inhibitor has only been evaluated in one pilot study using ipilimumab; however, no clinical benefit was observed in patients with synovial sarcoma. ${ }^{207}$ Recently, the IMMUNOSARC study, a phase II clinical trial which investigated the potential of treating advanced STS with a combination of the multi-targeted TKI sunitinib with the PD-1 inhibitor nivolumab, was completed. Promising results were observed with an overall and progression free survival of $77 \%$ and $50 \%$, respectively, at 6 months (NCT03277924). ${ }^{208}$ Chimeric antigen receptor T (CAR-T) adaptive cell therapy involves the isolation of a patient's own T-cells and modifying them to express a CAR that recognizes a specific tumor antigen and then reinjecting them into the patient. ${ }^{209}$ Recognition of the tumor cells by the CAR activates T-cell proliferation and elimination of the tumor cells. CAR-T cell therapy has proven to be promising for hematological cancers and is currently under investigation for solid tumors including sarcomas. ${ }^{210-212}$ A phase I/II clinical trial showed that HER2-CAR-T cells travel to the site of human epidermal growth factor receptor 2 (HER2)-positive sarcomas and persist for more than 6 weeks; the median overall survival ranged from 5.1 to 29.1 months without inducing toxicity (NCT00902044). ${ }^{213}$ A CAR-T cell therapy pilot study is currently undergo where the T-cells from myxoid liposarcoma patients were genetically engineered to recognize NY-ESO1, an antigen expressed in $80-90 \%$ of myxoid liposarcoma patients (NCT02992743). ${ }^{214}$ Interestingly, $70-80 \%$ of synovial sarcomas also express NY-ESO1, and T-cell receptor (TCR) treatment has recently gained FDA approval for patients with HLA-A*201, HLA$A^{*} 205$, or HLA-A*206 allele-positive advanced synovial sarcoma. $^{215-217}$ It may therefore be worthwhile to evaluate whether CAR-T cell therapy is superior to TCR treatment in synovial sarcomas. A phase I clinical trial that utilizes CAR-T cell therapy to target EGFR and CD19 to treat children and young adults with recurrent/refractory solid tumors is ongoing (NCT03618381). Preclinical studies have proven that CAR-T cell therapy targeting sarcoma-associated antigens is effective and ongoing clinical trials are evaluating its therapeutic potential (reviewed in ref. ${ }^{218}$ ).

\section{FUTURE DIRECTIONS}

Targeting oncogenic TFs

Historically, TFs were considered undruggable, but there is increasing preclinical and clinical evidence that their activity can be targeted. Indeed, TFs can be targeted by inhibiting their interactions with DNA or protein co-factors or by decreasing their protein stability through targeting the proteasome. ${ }^{219,220}$ Aberrant TF activity plays a critical role in simple and complex karyotype sarcomas, and recently there have been advances to target oncogenic fusion TFs in sarcomas. For example, trabectedin is clinically effective against leiomyosarcomas and liposarcomas where it interferes with the ability of FUS-CHOP to bind its target promoters. $^{221-223}$ Trabectedin was FDA-approved for these sarcoma subtypes in 2015 and is currently in clinical trials for other sarcoma subtypes (NCT02367924, NCT02275286, NCT04076579, NCT01303094, NCT04067115).

Emerging evidence has revealed that genome-editing systems and genetic approaches including clustered regularly interspaced short palindromic repeats associated protein 9 (CRISPR-Cas9) and RNA interference (RNAi) have therapeutic potential by directly targeting fusion oncogenes or their respective DNA-binding motifs. Indeed, CRISPR-Cas9-mediated knockdown of PAX3FOXO1 significantly reduced colony formation in a human myoblast model. ${ }^{224}$ Knockdown of EWSR1-FLI1 with CD99targeted nanoparticles carrying Cas9-EWSR1 sgRNA RNP led to reduced tumor growth in EwS xenografts. ${ }^{225}$ Deletion of the GGAA-microsatellite sequence regulating the activation of NROB1 by EWSR1/FLI1 using CRISPR-Cas9 led to reduced EwS cell proliferation and anchorage-independent growth. ${ }^{226}$ GGAAmicrosatellite repeats were found to be specifically active only in EwS, and silencing multiple repeats using CRISPR-Cas9 strongly decreased the expression of putative EWS-FLI1 target genes. ${ }^{227,228}$ Furthermore, targeting of a single SOX2-regulating GGAA-microsatellite enhancer abrogated EwS tumor growth in vivo. ${ }^{228}$ Martinez-Lage et al. recently proposed that non-homologous end joining (NHEJ) CRISPR-mediated deletion of fusion oncogenes is an efficient and selective strategy for cancer cell elimination. The authors showed that CRISPR-mediated EWR1-FLI1 deletion inhibited tumor growth in EwS xenografts and PDX models. Moreover, a combination of EWSR1-FLI1 deletion and doxorubicin was more effective compared to either monotherapy alone in xenograft models. ${ }^{229}$ Inhibiting expression of EWS-FLI1, ${ }^{230-232}$ PAX3FOXO1, ${ }^{233,234}$ and SYT-SSX ${ }^{235,236}$ by RNAi in vitro also significantly 
12

reduced cell viability and induced cell death. However, these antitumor effects were not always confirmed in vivo and siRNA delivery using nanoparticles, liposomes and recombinant exosomes has had limited success.

Approaches to target fusion oncoproteins by proteasome degradation or post-translational modifications have also been investigated. For example, treatment of synovial sarcoma cells with the HDACi FK228 (PubChem CID: 5352062) led to degradation of SYT-SSX and decreased cell viability and induced apoptosis. $^{237}$ Similarly, treatment of EwS cells with entinostat (PubChem CID: 4261), a HDAC1/3 inhibitor, led to reduced EWSFLI1 expression, a $G_{0} / G_{1}$ cell cycle arrest, DNA damage, caspase activation and apoptosis. ${ }^{238}$ PLK1, a serine/threonine kinase, phosphorylates and stabilizes PAX3-FOXO1 in ARMS cells, and when it was inhibited with a small molecule inhibitor BI 2536 (PubChem CID: 11364421), PAX3-FOXO1 was ubiquitinated and degraded and this corresponded with tumor regression in a xenograft mouse model. ${ }^{239}$ Similarly, $100 \%$ tumor regression was obtained in xenograft mouse models of ARMS using the PLK1inhibitor volasertib (BI 6727) (PubChem CID: 10461508). ${ }^{240}$ Furthermore, PAX3-FOXO1 activity is dependent on the epigenetic regulator bromodomain-containing protein 4 (BRD4) and inhibition of BRD4 with the small molecule inhibitor JQ1 (PubChem CID: 46907787) resulted in anti-cancer activity in preclinical models. ${ }^{241}$ The advantages and drawbacks of targeting oncogenic fusion TFs are further discussed in a recent editorial. ${ }^{242}$

The oncogenic c-Myc, which is amplified in a variety of sarcomas with simple and complex karyotypes, has been successfully targeted in preclinical studies and clinical trials using multiple approaches. Omomyc, a dominant negative c-Myc, interferes with the ability of c-Myc/Max complexes to bind and activate their target genes. ${ }^{243}$ In a preclinical model of lung adenocarcinoma, Omomyc slowed tumor growth, and when combined with paclitaxel (PubChem CID: 36314), almost completely abrogated tumor growth. ${ }^{244}$ Due to its high anti-cancer potential and limited side effects, Omomyc is about to reach clinical trials for lung, breast and colorectal cancers. Future preclinical and clinical studies should investigate the potential of Omomyc to treat c-Myc-driven sarcomas. BRD4 is involved in regulating C-Myc transcription, and its inhibition using JQ1 resulted in anti-cancer activity in rhabdomyosarcoma and EwS, among other cancers. ${ }^{241,245-248}$ While JQ1 treatment significantly reduced EwS cell proliferation and tumor growth in vivo, it did not result in a downregulation of c-Myc, indicating that BRD4 does not target c-Myc in EwS. ${ }^{249}$ Proteolysis targeting chimaeras (PROTACs), a technology that utilizes the ubiquitin-protease system to target proteins for proteasomal degradation, has shown better success than JQ1 in targeting BRD4. ${ }^{250}$ For example, ARV-825 (PubChem CID: 92044400) was designed to target BRD4 and it has greater ability than JQ1 or other small-molecule BRD4 inhibitors to downregulate levels of c-Myc and its downstream target genes. ${ }^{251,252}$ ARV-825 and ARV-771 (PubChem CID: 126619980) also have anti-cancer potential in MPNST cells by downregulating BRD4, inhibiting cell viability and inducing apoptosis. ${ }^{253}$ The PROTAC BET-d260 significantly downregulated BRD2,3,4 and c-Myc in a number of osteosarcoma cell lines and this was associated with tumor growth inhibition and apoptosis. ${ }^{254}$ Furthermore, PROTAC MD-224 (PubChem CID: 131986956) which efficiently targets MDM2, induced complete and durable tumor regression in leukemia cells in vivo, and it would be worth evaluating its activity in MDM2-driven sarcomas such as liposarcomas. ${ }^{255}$ Future clinical trials should evaluate whether targeting TFs either alone or in combination with other targeted therapeutic approaches can lead to more effective therapies and better outcomes for sarcoma patients.

Personalized precision medicine

Next generation sequencing (NGS) tools allows for rapid and costeffective sequencing of whole genome DNA and transcriptomic
RNA profiles which can be used for either diagnostic or therapeutic purposes. So far, they have enabled the generation of large gene expression signatures of downstream targets of genetic or chromosomal aberrations in specific sarcoma subtypes. These NGS tools are redefining the way we diagnose and treat sarcomas, as sarcomas are difficult to fully characterize even by expert pathologists. Rationally chosen drug treatment based on NGS data in individual patients could provide clinical benefit and should become the norm for sarcoma diagnosis and treatment. Furthermore, 3D-cell culture models such as spheroids and organoids derived from tumor tissue from a patient represent novel tools that can be used to identify personalized drug treatments. Importantly, these models are able to overcome limitations associated with traditional 2D-monolayer cell cultures and more realistically reflect tumor heterogeneity, cellextracellular matrix interactions and tumor microenvironment. ${ }^{256}$ Similarly, PDX models in which fresh patient tumor tissues are directly transplanted into immunocompromised mice, represent a novel approach to identify personalized drug treatments. They are superior to standard cell line-derived xenografts because they maintain the histological, epigenetic and genetic characteristics across several passages, and includes the tumor microenvironment, which together creates a more realistic model of the pathophysiological conditions of the patient's tumor. ${ }^{257,258}$ Indeed, copy number alterations found in PDX models of STS and bone sarcoma are also evident in sarcoma patients which suggest that these alterations are due to realistic tumor progression rather than model-specific artefacts. ${ }^{259}$ Furthermore, in vitro PDX cell lines and/or in vivo PDX mouse models enable researchers to perform high-throughput drug screens rapidly and inexpensively to design personalized treatments aimed at improving patient outcomes. Importantly, PDX models are highly predictive of clinical treatment response. ${ }^{260}$ This is evident in the response rates to standard chemotherapeutic and targeted therapies in PDX models correlating well with clinical outcome for a number of cancer patients including those with colorectal, pancreatic, non-small cell lung and breast cancer. ${ }^{261-265}$ Several studies have reported successful establishment of STS and bone sarcoma PDX models, with an overall engraftment success rate of $32-69 \%$ and successful recapitulation of the genetic and phenotypic characteristics of the original tumor. ${ }^{266-270}$ Furthermore, a high-throughput drug screen revealed that the most commonly used chemotherapeutics, HDAC and proteasome inhibitors, were active against most sarcoma subtypes. ${ }^{268}$ All rhabdomyosarcoma PDX models were particularly sensitive to the WEE1 inhibitor AZD1775 (PubChem CID: 24856436) and AZD1775 combined with current standard of care drugs vincristine (VCR) (PubChem CID: 5978) and irinotecan (IRN) (PubChem CID: 60838) had a better response rate in ERMS and ARMS PDX models compared to AZD1775, VCR and IRN alone. This demonstrates the advantage of using PDX models for personalized sarcoma therapy and justifies the use of a combination of the three drugs for future clinical trials. A summary of current personalized sarcoma treatment options is illustrated in Fig. 8.

\section{CONCLUSIONS}

Despite the identification of oncogenic factors and pathways that drive sarcomagenesis and the development of therapies to target some of them, the treatment of sarcomas still poses a huge therapeutic challenge. This is due to the vast array of sarcoma subtypes, their intrinsic heterogeneity, alterations in many signaling pathways and variability in response to treatment. Not surprisingly, monotherapy has not been effective in the treatment of sarcomas, and combination therapies that target multiple oncogenic pathways while minimizing drug toxicity should be considered in future. It is anticipated that this will be achieved by unravelling the molecular mechanisms of each sarcoma subtype 


\section{Personalized Sarcoma Treatment}

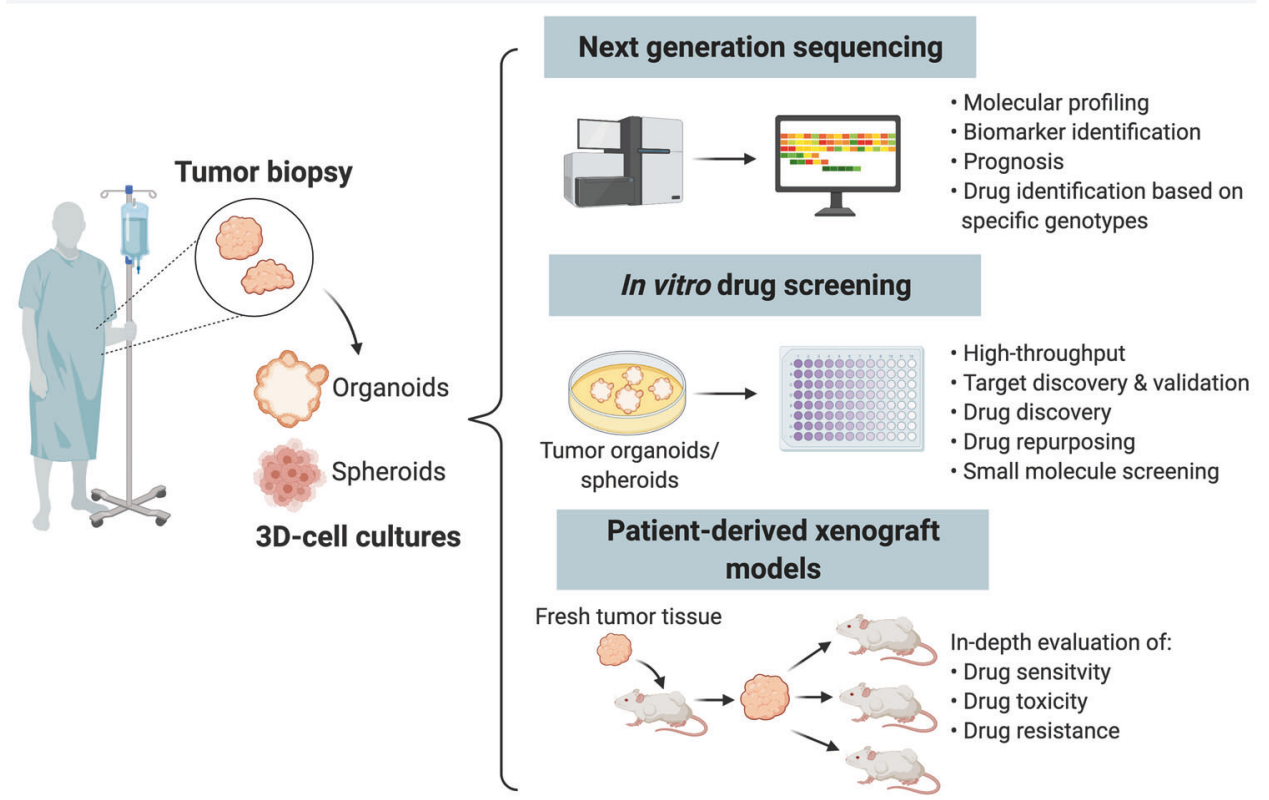

Fig. 8 Schematic illustration of personalized sarcoma treatment depicting workflow from sarcoma biopsy to next generation sequencing, in vitro drug screening, and patient-derived xenograft (PDX) models

and applying personalized medicine principles to treat these highly aggressive and often drug resistant cancers.

\section{ACKNOWLEDGEMENTS}

The figures in this manuscript were created using BioRender (https://biorender.com/) as part of the Academic License. The authors were supported by grants from the South Africa Medical Research Council (SAMRC), the National Research Foundation (NRF), Cancer Association of South Africa (CANSA) and the Universities of Cape Town and Pretoria.

\section{AUTHOR CONTRIBUTIONS}

Conceptualization: V.D. and S.P.; writing-original draft preparation: V.D. and S.P.; review and editing M.S.P.; V.D. drew the figures.

\section{ADDITIONAL INFORMATION}

Competing interests: The authors declare no competing interests.

\section{REFERENCES}

1. Fletcher, C. D. M., Bridge, J. A., Hogendoorn, P. \& Mertens, F. WHO Classification of Tumours of Soft Tissue and Bone (IARC Press, 2013).

2. Anttila, S. \& Boffetta, P. Occupational Cancers (Springer, 2020).

3. Zhao, X. \& Yue, C. Gastrointestinal stromal tumor. J. Gastrointest. Oncol. 3 189-208 (2012).

4. Burningham, Z., Hashibe, M., Spector, L. \& Schiffman, J. D. The epidemiology of sarcoma. Clin. Sarcoma Res. 2, 14 (2012). 10.1186/2045-3329-2-14.

5. Bray, F. et al. (eds) Cancer Incidence in Five Continents (Lyon: International Agency for Research on Cancer, 2017).

6. Brouns, F., Stas, M. \& De Wever, I. Delay in diagnosis of soft tissue sarcomas. Eur. J. Surg. Oncol. 29, 440-445 (2003).

7. Sarcoma UK. Impact of Sarcoma: National Sarcoma Survey 2020 (Sarcoma UK, 2020)

8. Raut, C. P. et al. High rates of histopathologic discordance in sarcoma with implications for clinical care. J. Clin. Oncol. 29, 10065-10065 (2011).

9. Soomers, V., Husson, O., Young, R., Desar, I. \& Van der Graaf, W. The sarcoma diagnostic interval: a systematic review on length, contributing factors and patient outcomes. ESMO Open 5, e000592 (2020).
10. Park, J. H., Kang, C. H., Kim, C. H., Chae, I. J. \& Park, J. H. Highly malignant soft tissue sarcoma of the extremity with a delayed diagnosis. World J. Surg. Oncol. 8 , 84 (2010).

11. Edwards, M., Halton, J., Ramphal, R. \& Johnston, D. Is time of the essence? Delayed diagnosis of Ewing's sarcoma. Case Rep. 2015, bcr2014208307-bcr2014208307 (2015).

12. Arifi, S., Belbaraka, R., Rahhali, R. \& Ismaili, N. Treatment of adult soft tissue sarcomas: an overview. Rare Cancers Ther. 3, 69-87 (2015).

13. Bleloch, J. S. et al. Managing sarcoma: where have we come from and where are we going? Ther. Adv. Med. Oncol. 9, 637-659 (2017).

14. Meyer, M. \& Seetharam, M. First-line therapy for metastatic soft tissue sarcoma. Curr. Treat. Options Oncol. 20, 6 (2019).

15. Carbonnaux, M. et al. Very long-term survivors among patients with metastatic soft tissue sarcoma. Cancer Med. 8, 1368-1378 (2019).

16. Mitelman, F., Johansson, B. \& Mertens, F. The impact of translocations and gene fusions on cancer causation. Nat. Rev. Cancer 7, 233-245 (2007).

17. Helman, L. J. \& Meltzer, P. Mechanisms of sarcoma development. Nat. Rev. Cancer 3, 685-694 (2003).

18. Osuna, D. \& de Alava, E. Molecular pathology of sarcomas. Rev. Recent Clin. Trials 4, 12-26 (2009).

19. Matushansky, I. \& Maki, R. G. Mechanisms of sarcomagenesis. Hematol. Oncol. Clin. North Am. 19, 427-449 (2005)

20. Malumbres, M. \& Barbacid, M. Cell cycle, CDKs and cancer: a changing paradigm. Nat. Rev. Cancer 9, 153-166 (2009).

21. Besson, A., Dowdy, S. F. \& Roberts, J. M. CDK inhibitors: cell cycle regulators and beyond. Dev. Cell 14, 159-169 (2008).

22. Li, J., Poi, M. J. \& Tsai, M.-D. Regulatory mechanisms of tumor suppressor P16 ${ }^{\text {INK4A }}$ and their relevance to cancer. Biochemistry 50, 5566-5582 (2011).

23. Harbour, J. W. The Rb/E2F pathway: expanding roles and emerging paradigms. Genes Dev. 14, 2393-2409 (2000).

24. Tao, W. \& Levine, A. J. P19ARF stabilizes p53 by blocking nucleo-cytoplasmic shuttling of Mdm2. Proc. Natl Acad. Sci. USA 96, 6937-6941 (1999).

25. Yu, J. \& Zhang, L. The transcriptional targets of p53 in apoptosis control. Biochem. Biophys. Res. Commun. 331, 851-858 (2005).

26. Bui, N. Q. et al. A clinico-genomic analysis of soft tissue sarcoma patients reveals CDKN2A deletion as a biomarker for poor prognosis. Clin. Sarcoma Res. 9, 12 (2019).

27. Leach, F. S. et al. p53 Mutation and MDM2 amplification in human soft tissue sarcomas. Cancer Res. 53, 2231-2234 (1993).

28. Gao, P., Seebacher, N. A., Hornicek, F., Guo, Z. \& Duan, Z. Advances in sarcoma gene mutations and therapeutic targets. Cancer Treat. Rev. 62, 98-109 (2018). 
29. Pérot, G. et al. Constant p53 pathway inactivation in a large series of soft tissue sarcomas with complex genetics. Am. J. Pathol. 177, 2080-2090 (2010).

30. Mayo, L. D. \& Donner, D. B. The PTEN, Mdm2, p53 tumor suppressor-oncoprotein network. Trends Biochem. Sci. 27, 462-467 (2002).

31. Movva, S. et al. Multi-platform profiling of over 2000 sarcomas: identification of biomarkers and novel therapeutic targets. Oncotarget 6, 12234-12247 (2015).

32. Barrios, C., Castresana, J. S., Ruiz, J. \& Kreicbergs, A. Amplification of the c-myc proto-oncogene in soft tissue sarcomas. Oncology 51, 13-17 (1994).

33. Castresana, J. S., Barrios, C., Gómez, L. \& Kreicbergs, A. No association between cmyc amplification and TP53 mutation in sarcoma tumorigenesis. Cancer Genet. Cytogenet. 76, 47-49 (1994).

34. Gamberi, G. et al. Prognostic relevance of C-myc gene expression in giant-cell tumor of bone. J. Orthop. Res. 16, 1-7 (1998).

35. Gamberi, G. et al. C-myc and c-fos in human osteosarcoma: prognostic value of mRNA and protein expression. Oncology 55, 556-563 (1998).

36. Sollazzo, M. R. et al. Increased C-MYC oncogene expression in Ewing's sarcoma: correlation with Ki67 proliferation index. Tumor J. 85, 167-173 (1999).

37. Barrios, C., Castresana, J. S., Ruiz, J. \& Kreicbergs, A. Amplification of c-myc oncogene and absence of c-Ha-ras point mutation in human bone sarcoma. J. Orthop. Res. 11, 556-563 (1993).

38. Demir, D. et al. Prognostic significance of bcl-2, c-myc, survivin and tumor grade in synovial sarcoma. Turkish J. Pathol. https://doi.org/10.5146/tjpath.2013.01221 (2013).

39. Yang, J. et al. Genetic aberrations in soft tissue leiomyosarcoma. Cancer Lett. 275, 1-8 (2009).

40. Eilers, M. \& Eisenman, R. N. Myc's broad reach. Genes Dev. 22, 2755-2766 (2008).

41. Grandori, C., Cowley, S. M., James, L. P. \& Eisenman, R. N. The Myc/Max/Mad network and the transcriptional control of cell behavior. Annu. Rev. Cell Dev. Biol. 16, 653-699 (2000).

42. Fernandez, P. C. et al. Genomic targets of the human c-Myc protein. Genes Dev. 17, 1115-29 (2003).

43. Nasi, S., Ciarapica, R., Jucker, R., Rosati, J. \& Soucek, L. Making decisions through Myc. FEBS Lett. 490, 153-162 (2001).

44. Wu, S. et al. Myc represses differentiation-induced p21CIP1 expression via Miz-1dependent interaction with the p21 core promoter. Oncogene 22, 351-360 (2003).

45. Zhang, J. et al. c-Myc promotes tumor proliferation and anti-apoptosis by repressing p21 in rhabdomyosarcomas. Mol. Med. Rep. 16, 4089-4094 (2017).

46. Milewski, D. et al. FoxF1 and FoxF2 transcription factors synergistically promote rhabdomyosarcoma carcinogenesis by repressing transcription of p21Cip1 CDK inhibitor. Oncogene 36, 850-862 (2017).

47. Nakatani, F. et al. Identification of p21 WAF1/CIP1 as a direct target of EWS-Fli1 oncogenic fusion protein. J. Biol. Chem. 278, 15105-15115 (2003).

48. Willmer, T., Cooper, A., Sims, D., Govender, D. \& Prince, S. The T-box transcription factor 3 is a promising biomarker and a key regulator of the oncogenic phenotype of a diverse range of sarcoma subtypes. Oncogenesis 5, e199 (2016).

49. Willmer, T., Peres, J., Mowla, S., Abrahams, A. \& Prince, S. The T-box factor TBX3 is important in S-phase and is regulated by c-MYC and cyclin A-CDK2. Cell Cycle 14, 3173-3183 (2015).

50. Sims, D. et al. The c-myc/AKT1/TBX3 axis is important to target in the treatment of embryonal rhabdomyosarcoma. Cancers 12, 1-21 (2020).

51. Lee, S. B. et al. The EWS-WT1 translocation product induces PDGFA in desmoplastic small round-cell tumour. Nat. Genet. 17, 309-313 (1997)

52. McGary, E. C. et al. Inhibition of platelet-derived growth factor-mediated proliferation of osteosarcoma cells by the novel tyrosine kinase inhibitor STI571. Clin. Cancer Res. 8, 3584-3591 (2002).

53. Zheng, S., Chen, L.-R., Wang, H.-J. \& Chen, S.-Z. Analysis of mutation and expression of c-kit and PDGFR-alpha gene in gastrointestinal stromal tumor. Hepatogastroenterology 54, 2285-2290 (2007).

54. Heinrich, M. C. et al. PDGFRA activating mutations in gastrointestinal stromal tumors. Science 299, 708-710 (2003).

55. Rubin, B. P. et al. KIT activation is a ubiquitous feature of gastrointestinal stromal tumors. Cancer Res. 61, 8118-8121 (2001).

56. Hornick, J. L. \& Fletcher, C. D. M. Immunohistochemical staining for KIT (CD117) in soft tissue sarcomas is very limited in distribution. Am. J. Clin. Pathol. 117, 188-193 (2002).

57. Ferracini, R. et al. Retrogenic expression of the MET proto-oncogene correlates with the invasive phenotype of human rhabdomyosarcomas. Oncogene 12 , 1697-1705 (1996).

58. Oda, Y. et al. Expression of hepatocyte growth factor (HGF)/scatter factor and its receptor c-MET correlates with poor prognosis in synovial sarcoma. Hum. Pathol. 31, 185-192 (2000).

59. Mancarella, C. \& Scotlandi, K. 40 years of IGF1: IGF system in sarcomas: a crucial pathway with many unknowns to exploit for therapy. J. Mol. Endocrinol. 61, T45-T60 (2018).
60. Stambolic, V. et al. Negative regulation of PKB/Akt-dependent cell survival by the tumor suppressor PTEN. Cell 95, 29-39 (1998).

61. Mita, M. M. \& Tolcher, A. W. The role of mTOR inhibitors for treatment of sarcomas. Curr. Oncol. Rep. 9, 316-322 (2007).

62. Schaefer, K.-L. et al. Microarray analysis of Ewing's sarcoma family of tumours reveals characteristic gene expression signatures associated with metastasis and resistance to chemotherapy. Eur. J. Cancer 44, 699-709 (2008).

63. Lo, W. W., Pinnaduwage, D., Gokgoz, N., Wunder, J. S. \& Andrulis, I. L. Aberrant Hedgehog signaling and clinical outcome in osteosarcoma. Sarcoma 2014, 1-9 (2014).

64. Pressey, J. G., Anderson, J. R., Crossman, D. K., Lynch, J. C. \& Barr, F. G. Hedgehog pathway activity in pediatric embryonal rhabdomyosarcoma and undifferentiated sarcoma: a report from the Children's Oncology Group. Pediatr. Blood Cancer 57, 930-938 (2011)

65. Tiet, T. D. et al. Constitutive hedgehog signaling in chondrosarcoma upregulates tumor cell proliferation. Am. J. Pathol. 168, 321-330 (2006).

66. Pridgeon, M. G., Grohar, P. J., Steensma, M. R. \& Williams, B. O. Wnt signaling in Ewing sarcoma, osteosarcoma, and malignant peripheral nerve sheath tumors. Curr. Osteoporos. Rep. 15, 239-246 (2017).

67. Vijayakumar, S. et al. High-frequency canonical Wnt activation in multiple sarcoma subtypes drives proliferation through a TCF/ $\beta$-Catenin target gene, CDC25A. Cancer Cell 19, 601-612 (2011).

68. Cossetti, C., Gualtieri, A., Pomella, S., Carcarino, E. \& Rota, R. Notch signaling in pediatric soft tissue sarcoma. In Miele, L., Artavanis-Tsakonas, S. (eds) Targeting Notch in Cancer. 277-312 (Springer New York, 2018).

69. Merritt, N. M. et al. A comprehensive evaluation of Hippo pathway silencing in sarcomas. Oncotarget 9, 31620-31636 (2018).

70. Fullenkamp, C. A. et al. TAZ and YAP are frequently activated oncoproteins in sarcomas. Oncotarget 7, 30094-30108 (2016).

71. Hanahan, D. \& Weinberg, R. A. Hallmarks of cancer: the next generation. Cell 144, 646-674 (2011).

72. Cross, M. J. \& Claesson-Welsh, L. FGF and VEGF function in angiogenesis: signalling pathways, biological responses and therapeutic inhibition. Trends Pharmacol. Sci. 22, 201-207 (2001).

73. Hicklin, D. J. \& Ellis, L. M. Role of the vascular endothelial growth factor pathway in tumor growth and angiogenesis. J. Clin. Oncol. 23, 1011-1027 (2005).

74. Chao, C. et al. Vascular endothelial growth factor and soft tissue sarcomas: tumor expression correlates with grade. Ann. Surg. Oncol. 8, 260-267 (2001).

75. Feng, Q. et al. High expression of SDF-1 and VEGF is associated with poor prognosis in patients with synovial sarcomas. Exp. Ther. Med. https://doi.org/ 10.3892/etm.2018.5684 (2018).

76. Potti, A. et al. Determination of vascular endothelial growth factor (VEGF) overexpression in soft tissue sarcomas and the role of overexpression in leiomyosarcoma. J. Cancer Res. Clin. Oncol. 130, 52-56 (2004).

77. Yudoh, K. et al. Concentration of vascular endothelial growth factor in the tumour tissue as a prognostic factor of soft tissue sarcomas. Br. J. Cancer 84, 1610-1615 (2001).

78. Kampmann, E. et al. VEGFR2 predicts decreased patients survival in soft tissue sarcomas. Pathol.-Res. Pract. 211, 726-730 (2015).

79. Kaya, M. et al. Vascular endothelial growth factor expression in untreated osteosarcoma is predictive of pulmonary metastasis and poor prognosis. Clin. Cancer Res. 6, 572-577 (2000).

80. Zhang, L. et al. Vascular endothelial growth factor overexpression by soft tissue sarcoma cells: implications for tumor growth, metastasis, and chemoresistance. Cancer Res. 66, 8770-8778 (2006).

81. Kalluri, R. \& Weinberg, R. A. The basics of epithelial-mesenchymal transition. J. Clin. Investig. 119, 1420-1428 (2009).

82. Stemmler, M. P., Eccles, R. L., Brabletz, S. \& Brabletz, T. Non-redundant functions of EMT transcription factors. Nat. Cell Biol. 21, 102-112 (2019).

83. Xu, J., Lamouille, S. \& Derynck, R. TGF- $\beta$-induced epithelial to mesenchymal transition. Cell Res. 19, 156-172 (2009).

84. Sannino, G., Marchetto, A., Kirchner, T. \& Grünewald, T. G. P. Epithelial-tomesenchymal and mesenchymal-to-epithelial transition in mesenchymal tumors: a paradox in sarcomas? Cancer Res. 77, 4556-4561 (2017).

85. Li, G. et al. Slug signaling is up-regulated by CCL21/CXCR7 to induce EMT in human chondrosarcoma. Med. Oncol. 32, 2 (2015).

86. Srivastava, R. K. et al. GLI inhibitor GANT-61 diminishes embryonal and alveolar rhabdomyosarcoma growth by inhibiting Shh/AKT-mTOR axis. Oncotarget 5, 12151-12165 (2014).

87. Skrzypek, K. et al. SNAIL promotes metastatic behavior of rhabdomyosarcoma by increasing EZRIN and AKT expression and regulating microRNA networks. Cancers 12, 1870 (2020).

88. Fitzgerald, M. P. et al. Human chondrosarcoma cells acquire an epithelial-like gene expression pattern via an epigenetic switch: evidence for mesenchymal-epithelial transition during sarcomagenesis. Sarcoma 2011, 1-11 (2011). 
89. Qi, Y. et al. The correlation between morphology and the expression of TGF- $\beta$ signaling pathway proteins and epithelial-mesenchymal transition-related proteins in synovial sarcomas. Int. J. Clin. Exp. Pathol. 6, 2787-2799 (2013).

90. Lee, K.-W., Lee, N. K., Ham, S., Roh, T.-Y. \& Kim, S.-H. Twist1 is essential in maintaining mesenchymal state and tumor-initiating properties in synovial sarcoma. Cancer Lett. 343, 62-73 (2014).

91. Saito, T., Nagai, M. \& Ladanyi, M. SYT-SSX1 and SYT-SSX2 interfere with repression of E-cadherin by snail and slug: a potential mechanism for aberrant mesenchymal to epithelial transition in human synovial sarcoma. Cancer Res. $\mathbf{6 6}$, 6919-6927 (2006).

92. Somarelli, J. A. et al. Mesenchymal-epithelial transition in sarcomas is controlled by the combinatorial expression of microRNA 200s and GRHL2. Mol. Cell. Biol. 36, 2503-2513 (2016)

93. Chen, Y., Zhang, K., Li, Y. \& He, Q. Estrogen-related receptor a participates transforming growth factor- $\beta$ (TGF- $\beta$ ) induced epithelial-mesenchymal transition of osteosarcoma cells. Cell Adh. Migr. 11, 338-346 (2017).

94. Chen, J. et al. MicroRNA-130a promotes the metastasis and epithelialmesenchymal transition of osteosarcoma by targeting PTEN. Oncol. Rep. 35, 3285-3292 (2016).

95. Tian, K., Di, R. \& Wang, L. MicroRNA-23a enhances migration and invasion through PTEN in osteosarcoma. Cancer Gene Ther. 22, 351-359 (2015).

96. Tian, H. et al. Bone morphogenetic protein-2 promotes osteosarcoma growth by promoting epithelial-mesenchymal transition (EMT) through the Wnt/ $\beta$-catenin signaling pathway. J. Orthop. Res. 37, 1638-1648 (2019).

97. Wensman, H. et al. Extensive expression of craniofacial related homeobox genes in canine mammary sarcomas. Breast Cancer Res. Treat. 118, 333-343 (2009).

98. Guo, Y. et al. Blocking Wnt/LRP5 signaling by a soluble receptor modulates the epithelial to mesenchymal transition and suppresses met and metalloproteinases in osteosarcoma Saos-2 cells. J. Orthop. Res. 25, 964-971 (2007).

99. Wang, S., Zhao, G., Zhao, S., Qiao, Y. \& Yang, H. The effects of Interleukin-33 (IL-33) on osteosarcoma cell viability, apoptosis, and epithelial-mesenchymal transition are mediated through the PI3K/AKT pathway. Med. Sci. Monit. 26, e920766 (2020).

100. Alford, S. H. et al. Matrix metalloproteinase expression in high grade soft tissue sarcomas. Oncol. Rep. 18, 1529-1536 (2007).

101. Bjørnland, K. et al. Matrix metalloproteinases participate in osteosarcoma invasion. J. Surg. Res. 127, 151-156 (2005).

102. Zhang, M. \& Zhang, X. Association of MMP-2 expression and prognosis in osteosarcoma patients. Int. J. Clin. Exp. Pathol. 8, 14965-14970 (2015).

103. Feng, $T$. et al. The microRNA-708-5p/ZEB1/EMT axis mediates the metastatic potential of osteosarcoma. Oncol. Rep. 43, 491-502 (2019).

104. Jiang, R., Zhang, C., Liu, G., Gu, R. \& Wu, H. MicroRNA-126 inhibits proliferation, migration, invasion, and EMT in osteosarcoma by targeting ZEB1. J. Cell. Biochem. 118, 3765-3774 (2017).

105. Yi, L., Liu, M. \& Tang, Z. MicroRNA-130a inhibits growth and metastasis of osteosarcoma cells by directly targeting ZEB1. Mol. Med. Rep. 16, 3606-3612 (2017).

106. Ye, C., Yu, X., Liu, X., Dai, M. \& Zhang, B. miR-30d inhibits cell biological progression of Ewing's sarcoma by suppressing the MEK/ERK and PI3K/Akt pathways in vitro. Oncol. Lett. 15, 4390-4396 (2018).

107. Ding, J. et al. Identification of upstream miRNAs of SNAI2 and their influence on the metastasis of gastrointestinal stromal tumors. Cancer Cell Int. 19, 289 (2019).

108. Sachdeva, M. et al. MicroRNA-182 drives metastasis of primary sarcomas by targeting multiple genes. J. Clin. Investig. 124, 4305-4319 (2014).

109. Nezu, Y. et al. MiR-135b, a key regulator of malignancy, is linked to poor prognosis in human myxoid liposarcoma. Oncogene 35, 6177-6188 (2016).

110. Sun, X., Charbonneau, C., Wei, L., Chen, Q. \& Terek, R. M. miR-181a targets RGS16 to promote chondrosarcoma growth, angiogenesis, and metastasis. Mol. Cancer Res. 13, 1347-1357 (2015).

111. Dai, J. et al. Exosomes: key players in cancer and potential therapeutic strategy. Signal Transduct. Target. Ther. 5, 145 (2020).

112. Chicón-Bosch, M. \& Tirado, O. M. Exosomes in bone sarcomas: key players in metastasis. Cells 9, 241 (2020).

113. Casadei, L. et al. Exosome-derived miR-25-3p and miR-92a-3p stimulate liposarcoma progression. Cancer Res. 77, 3846-3856 (2017).

114. An, T. et al. Exosomes serve as tumour markers for personalized diagnostics owing to their important role in cancer metastasis. J. Extracell. Vesicles 4, 27522 (2015).

115. Nishida-Aoki, N. et al. Disruption of circulating extracellular vesicles as a novel therapeutic strategy against cancer metastasis. Mol. Ther. 25, 181-191 (2017).

116. Shimbo, K. et al. Exosome-formed synthetic microRNA-143 is transferred to osteosarcoma cells and inhibits their migration. Biochem. Biophys. Res. Commun. 445, 381-387 (2014).

117. Osaki, M. et al. MicroRNA-143 regulates human osteosarcoma metastasis by regulating matrix metalloprotease-13 expression. Mol. Ther. 19, 1123-1130 (2011).
118. Zhang, Y. et al. Microvesicle-mediated delivery of transforming growth factor B1 siRNA for the suppression of tumor growth in mice. Biomaterials $\mathbf{3 5}$ 4390-4400 (2014)

119. Rodriguez, R., Rubio, R. \& Menendez, P. Modeling sarcomagenesis using multipotent mesenchymal stem cells. Cell Res. 22, 62-77 (2012).

120. Lye, K. L., Nordin, N., Vidyadaran, S. \& Thilakavathy, K. Mesenchymal stem cells: from stem cells to sarcomas. Cell Biol. Int. 40, 610-618 (2016).

121. Rodriguez, R. et al. FUS-CHOP fusion protein expression coupled to p53 deficiency induces liposarcoma in mouse but not in human adipose-derived mesenchymal stem/stromal cells. Stem Cells 29, 179-192 (2011).

122. Shimizu, T. et al. C-MYC overexpression with loss of Ink4a/Arf transforms bone marrow stromal cells into osteosarcoma accompanied by loss of adipogenesis. Oncogene 29, 5687-5699 (2010).

123. Rodriguez, R. et al. Expression of FUS-CHOP fusion protein in immortalized/ transformed human mesenchymal stem cells drives mixoid liposarcoma formation. Stem Cells 31, 2061-2072 (2013).

124. Riggi, N. et al. EWS-FLI-1 expression triggers a ewing's sarcoma initiation program in primary human mesenchymal stem cells. Cancer Res. 68, 2176-2185 (2008).

125. Melnik, S. et al. Impact of c-MYC expression on proliferation, differentiation, and risk of neoplastic transformation of human mesenchymal stromal cells. Stem Cell Res. Ther. 10, 1-18 (2019).

126. Wang, J.-Y. et al. Generation of osteosarcomas from a combination of $\mathrm{Rb}$ silencing and c-Myc overexpression in human mesenchymal stem cells. Stem Cells Transl. Med. 6, 512-526 (2016).

127. Gambera, S. et al. Role of activator protein-1 complex on the phenotype of human osteosarcomas generated from mesenchymal stem cells. Stem Cells 1-14 (2018). https://doi.org/10.1002/stem.2869.

128. Kim, Y. J. et al. Co-expression of MDM2 and CDK4 in transformed human mesenchymal stem cells causes high-grade sarcoma with a dedifferentiated liposarcoma-like morphology. Lab. Investig. 99, 1309-1320 (2019).

129. Vishnubalaji, R. et al. Neoplastic transformation of human mesenchymal stromal cells mediated via LIN28B. Sci. Rep. 9, 1-14 (2019).

130. Abarrategi, A. et al. Osteosarcoma: cells-of-origin, cancer stem cells, and targeted therapies. Stem Cells Int. 2016, 1-13 (2016).

131. Lin, Y.-H. et al. Osteosarcoma: molecular pathogenesis and iPSC modeling. Trends Mol. Med. 23, 737-755 (2017).

132. Sottnik, J. L. et al. Osteocytes serve as a progenitor cell of osteosarcoma. J. Cell. Biochem. 115, 1420-1429 (2014).

133. Berman, S. D. et al. Metastatic osteosarcoma induced by inactivation of Rb and p53 in the osteoblast lineage. Proc. Natl Acad. Sci. USA 105, 11851-11856 (2008).

134. Walkley, C. R. et al. Conditional mouse osteosarcoma, dependent on p53 loss and potentiated by loss of Rb, mimics the human disease. Genes Dev. 22, 1662-1676 (2008).

135. Lin, P. P. et al. Targeted mutation of p53 and Rb in mesenchymal cells of the limb bud produces sarcomas in mice. Carcinogenesis 30, 1789-1795 (2009).

136. Mutsaers, A. J. et al. Modeling distinct osteosarcoma subtypes in vivo using Cre: lox and lineage-restricted transgenic shRNA. Bone 55, 166-178 (2013).

137. Tao, J. et al. Notch activation as a driver of osteogenic sarcoma. Cancer Cell 26, 390-401 (2014)

138. Chan, L. H. et al. Hedgehog signaling induces osteosarcoma development through Yap1 and H19 overexpression. Oncogene 33, 4857-4866 (2014).

139. Rubio, $R$. et al. The differentiation stage of p53-Rb-deficient bone marrow mesenchymal stem cells imposes the phenotype of in vivo sarcoma development. Oncogene 32, 4970-4980 (2013).

140. Yang, Y. et al. Genetically transforming human osteoblasts to sarcoma: development of an osteosarcoma model. Genes Cancer 8, 484-494 (2017).

141. Quist, T. et al. The impact of osteoblastic differentiation on osteosarcomagenesis in the mouse. Oncogene 34, 4278-4284 (2015).

142. Mutsaers, A. J. \& Walkley, C. R. Cells of origin in osteosarcoma: mesenchymal stem cells or osteoblast committed cells? Bone 62, 56-63 (2014).

143. Riggi, N. et al. Development of Ewing's sarcoma from primary bone marrowderived mesenchymal progenitor cells. Cancer Res. 65, 11459-11468 (2005).

144. Castillero-Trejo, Y., Eliazer, S., Xiang, L., Richardson, J. A. \& Ilaria, R. L. Expression of the EWS/FLI-1 oncogene in murine primary bone-derived cells results in EWS/ FLI-1-dependent, Ewing sarcoma-like tumors. Cancer Res. 65, 8698-8705 (2005).

145. Riggi, N. et al. Expression of the FUS-CHOP fusion protein in primary mesenchymal progenitor cells gives rise to a model of myxoid liposarcoma. Cancer Res. 66, 7016-7023 (2006).

146. Haldar, M., Hancock, J. D., Coffin, C. M., Lessnick, S. L. \& Capecchi, M. R. A conditional mouse model of synovial sarcoma: insights into a myogenic origin. Cancer Cell 11, 375-388 (2007).

147. Grimer, R., Judson, I., Peake, D. \& Seddon, B. Guidelines for the management of soft tissue sarcomas. Sarcoma 1-15 (2010). https://doi.org/10.1155/2010/ 506182. 
148. Grimer, R. et al. UK guidelines for the management of bone sarcomas. Sarcoma 1-14 (2010). https://doi.org/10.1155/2010/317462.

149. Sborov, D. \& Chen, J. L. Targeted therapy in sarcomas other than GIST tumors. J. Surg. Oncol. 111, 632-640 (2015).

150. Italiano, A. et al. Trends in survival for patients with metastatic soft-tissue. Sarcoma Cancer 117, 1049-1054 (2011).

151. Kohlmeyer, J. L. et al. CDKs in sarcoma: mediators of disease and emerging therapeutic targets. Int. J. Mol. Sci. 21, 3018 (2020).

152. Ballatori, S. E. \& Hinds, P. W. Osteosarcoma: prognosis plateau warrants retinoblastoma pathway targeted therapy. Signal Transduct. Target. Ther. 1, 16001 (2016).

153. Kohlmeyer, J. L. et al. RABL6A is an essential driver of MPNSTs that negatively regulates the RB1 pathway and sensitizes tumor cells to CDK4/6 inhibitors. Clin. Cancer Res. 26, 2997-3011 (2020).

154. Herrera-Abreu, M. T. et al. Early adaptation and acquired resistance to CDK4/6 inhibition in estrogen receptor-positive breast cancer. Cancer Res. 76, 2301-2313 (2016).

155. Pandey, K. et al. Molecular mechanisms of resistance to CDK4/6 inhibitors in breast cancer: a review. Int. J. Cancer 145, 1179-1188 (2019).

156. Kimura, $\mathrm{H}$. et al. Detection of MDM2 gene amplification in soft tissue sarcoma by FISH. J. Clin. Oncol. 32, 10562-10562 (2014).

157. Heymann, D. \& Rédini, F. Targeted therapies for bone sarcomas. Bonekey Rep. 2, 378 (2013).

158. Laroche-Clary, A. et al. Combined targeting of MDM2 and CDK4 is synergistic in dedifferentiated liposarcomas. J. Hematol. Oncol. 10, 123 (2017).

159. Balachandran, V. P. \& DeMatteo, R. P. Gastrointestinal stromal tumors. Adv. Surg. 48, 165-183 (2014)

160. Dagher, R. et al. Approval summary: imatinib mesylate in the treatment of metastatic and/or unresectable malignant gastrointestinal stromal tumors. Clin. Cancer Res. 8, 3034-3038 (2002).

161. Serrano, C. \& George, S. Recent advances in the treatment of gastrointestinal stromal tumors. Ther. Adv. Med. Oncol. 6, 115-127 (2014).

162. Demetri, G. D. et al. Efficacy and safety of imatinib mesylate in advanced gastrointestinal stromal tumors. N. Engl. J. Med. 347, 472-480 (2002).

163. Blanke, C. D. et al. Long-term results from a randomized Phase II Trial of standard- versus higher-dose imatinib mesylate for patients with unresectable or metastatic gastrointestinal stromal tumors expressing KIT. J. Clin. Oncol. 26, 620-625 (2008).

164. Chugh, R. et al. Phase II Multicenter Trial of Imatinib in 10 histologic subtypes of sarcoma using a Bayesian hierarchical statistical model. J. Clin. Oncol. 27, 3148-3153 (2009).

165. Sugiura, H. et al. Multicenter Phase II trial assessing effectiveness of imatinib mesylate on relapsed or refractory KIT-positive or PDGFR-positive sarcoma. J. Orthop. Sci. 15, 654-660 (2010).

166. Cranmer, L., Loggers, E. \& Pollack, S. Pazopanib in the management of advanced soft tissue sarcomas. Ther. Clin. Risk Manag. 941, (2016) https://doi.org/10.2147/ TCRM.S84792.

167. van der Graaf, W. T. et al. Pazopanib for metastatic soft-tissue sarcoma (PALETTE): a randomised, double-blind, placebo-controlled phase 3 trial. Lancet 379, 1879-1886 (2012).

168. Ronellenfitsch, U. et al. Preoperative pazopanib in high-risk soft tissue sarcoma: Phase II window-of opportunity study of the German Interdisciplinary Sarcoma Group (NOPASS/GISG-04). Ann. Surg. Oncol. 26, 1332-1339 (2019).

169. Brämswig, K. et al. Sorafenib in advanced, heavily pretreated patients with soft tissue sarcomas. Anticancer. Drugs 25, 848-853 (2014).

170. Santoro, A. et al. Phase II prospective study with sorafenib in advanced soft tissue sarcomas after anthracycline-based therapy. Ann. Oncol. 24, 1093-1098 (2013).

171. Maki, R. G. et al. Phase II Study of sorafenib in patients with metastatic or recurrent sarcomas. J. Clin. Oncol. 27, 3133-3140 (2009).

172. Gounder, M. M. et al. Sorafenib for advanced and refractory desmoid tumors. $N$. Engl. J. Med. 379, 2417-2428 (2018).

173. García del Muro, X. et al. Phase II trial of ifosfamide in combination with the VEGFR inhibitor sorafenib in advanced soft tissue sarcoma: a Spanish group for research on sarcomas (GEIS) study. Invest. N. Drugs 36, 468-475 (2018).

174. D'Adamo, D. R. et al. A Phase II trial of sorafenib and dacarbazine for leiomyosarcoma, synovial sarcoma, and malignant peripheral nerve sheath tumors. Oncologist 24, 857-863 (2019).

175. Que, Y. et al. Treatment-related adverse effects with pazopanib, sorafenib and sunitinib in patients with advanced soft tissue sarcoma: a pooled analysis. Cancer Manag. Res. ume 10, 2141-2150 (2018).

176. Liu, J. et al. ZD6474, a new treatment strategy for human osteosarcoma, and its potential synergistic effect with celecoxib. Oncotarget 6, 21341-21352 (2015).

177. Deshpande, H., Roman, S., Thumar, J. \& Sosa, J. A. Vandetanib (ZD6474) in the treatment of medullary thyroid cancer. Clin. Med. Insights Oncol. 5, CMO.S6197 (2011)
178. Wilding, C. P. et al. The landscape of tyrosine kinase inhibitors in sarcomas: looking beyond pazopanib. Expert Rev. Anticancer Ther. 19, 971-991 (2019).

179. Liu, B., Ding, F., Zhang, D. \& Wei, G. Risk of venous and arterial thromboembolic events associated with VEGFR-TKIs: a meta-analysis. Cancer Chemother. Pharmacol. 80, 487-495 (2017).

180. Massey, P. R., Okman, J. S., Wilkerson, J. \& Cowen, E. W. Tyrosine kinase inhibitors directed against the vascular endothelial growth factor receptor (VEGFR) have distinct cutaneous toxicity profiles: a meta-analysis and review of the literature. Support. Care Cancer 23, 1827-1835 (2015).

181. Schöffski, P. et al. An open-label, phase 2 study evaluating the efficacy and safety of the anti-IGF-1R antibody cixutumumab in patients with previously treated advanced or metastatic soft-tissue sarcoma or Ewing family of tumours. Eur. J. Cancer 49, 3219-3228 (2013).

182. Pappo, A. S. et al. A phase 2 trial of R1507, a monoclonal antibody to the insulinlike growth factor-1 receptor (IGF-1R), in patients with recurrent or refractory rhabdomyosarcoma, osteosarcoma, synovial sarcoma, and other soft tissue sarcomas: results of a Sarcoma Alliance. Cancer 120, 2448-2456 (2014).

183. Toretsky, J. A. \& Gorlick, R. IGF-1R targeted treatment of sarcoma. Lancet Oncol. 11, 105-106 (2010).

184. Guenther, L. M. et al. A combination CDK4/6 and IGF1R inhibitor strategy for Ewing Sarcoma. Clin. Cancer Res. 25, 1343-1357 (2019).

185. Chawla, S. P. et al. Phase II Study of the mammalian target of rapamycin inhibitor ridaforolimus in patients with advanced bone and soft tissue sarcomas. J. Clin. Oncol. 30, 78-84 (2012).

186. Demetri, G. D. et al. Results of an International Randomized Phase III Trial of the mammalian target of rapamycin inhibitor ridaforolimus versus placebo to control metastatic sarcomas in patients after benefit from prior chemotherapy. J. Clin. Oncol. 31, 2485-2492 (2013).

187. Wang, X., Goldstein, D., Crowe, P. \& Yang, J.-L. Synergistic effect of targeting both CDK4/6 and mTOR in sarcoma cell lines. In Experimental and Molecular Therapeutics 3907-3907 (American Association for Cancer Research, 2019).

188. Sanaei, M. \& Kavoosi, F. Histone deacetylases and histone deacetylase inhibitors: molecular mechanisms of action in various cancers. Adv. Biomed. Res. 8, 63 (2019).

189. van Maldegem, A. M., Bovée, J. V. M. G. \& Gelderblom, H. Panobinostat-a potential treatment for metastasized Ewing sarcoma? A case report. Pediatr. Blood Cancer 63, 1840-1843 (2016).

190. Cassier, P. A. et al. A phase II trial of panobinostat in patients with advanced pretreated soft tissue sarcoma. A study from the French Sarcoma Group. Br. J. Cancer 109, 909-914 (2013).

191. Booth, L., Roberts, J. L., Poklepovic, A. \& Dent, P. The lethality of [Pazopanib + HDAC Inhibitors] is enhanced by neratinib. Front. Oncol. 9, 650 (2019).

192. Tavallai, S., Hamed, H. A., Grant, S., Poklepovic, A. \& Dent, P. Pazopanib and HDAC inhibitors interact to kill sarcoma cells. Cancer Biol. Ther. 15, 578-585 (2014).

193. Thomas, S. et al. A phase I trial of panobinostat and epirubicin in solid tumors with a dose expansion in patients with sarcoma. Ann. Oncol. 27, 947-952 (2016).

194. Rothbart, S. B. \& Baylin, S. B. Epigenetic therapy for epithelioid sarcoma. Cell 181, 211 (2020).

195. Zhang, P. \& Pollock, R. E. Epigenetic regulators: new therapeutic targets for soft tissue sarcoma. Cancer Cell Microenviron. 1, e191 (2014).

196. Slemmons, K. K. et al. Targeting Hippo-dependent and Hippo-independent YAP1 signaling for the treatment of childhood rhabdomyosarcoma. Cancer Res. canres.3853.2019 (2020). https://doi.org/10.1158/0008-5472.CAN-19-3853.

197. Amé, J.-C., Spenlehauer, C. \& de Murcia, G. The PARP superfamily. BioEssays 26 , 882-893 (2004).

198. Sachdev, E., Tabatabai, R., Roy, V., Rimel, B. J. \& Mita, M. M. PARP inhibition in cancer: an update on clinical development. Target. Oncol. 14, 657-679 (2019).

199. Chen, A. PARP inhibitors: its role in treatment of cancer. Chin. J. Cancer 30 , 463-471 (2011).

200. Mangoni, M. et al. Soft tissue sarcomas: new opportunity of treatment with PARP inhibitors? Radiol. Med. 124, 282-289 (2019).

201. Grignani, G. et al. Trabectedin and olaparib in patients with advanced and nonresectable bone and soft-tissue sarcomas (TOMAS): an open-label, phase 1b study from the Italian Sarcoma Group. Lancet Oncol. 19, 1360-1371 (2018).

202. Grignani, G. et al. A phase $1 \mathrm{~b}$ trial with the combination of trabectedin and olaparib in relapsed patients (pts) with advanced and unresectable bone and soft tissue sarcomas (BSTS): an Italian Sarcoma Group (ISG) study. J. Clin. Oncol. 34, 11018-11018 (2016).

203. Perez, M. et al. Sarcoma stratification by combined $\mathrm{pH} 2 \mathrm{AX}$ and MAP17 (PDZK1IP1) levels for a better outcome on doxorubicin plus olaparib treatment. Signal Transduct. Target. Ther. 5, 195 (2020).

204. Vinay, D. S. et al. Immune evasion in cancer: mechanistic basis and therapeutic strategies. Semin. Cancer Biol. 35, S185-S198 (2015). 
205. Italiano, A., Bellera, C. \& D'Angelo, S. PD1/PD-L1 targeting in advanced softtissue sarcomas: a pooled analysis of phase II trials. J. Hematol. Oncol. 13, 55 (2020).

206. Molgora, M. et al. TREM2 modulation remodels the tumor myeloid landscape enhancing anti-PD-1 immunotherapy. Cell 182, 886-900.e17 (2020).

207. Maki, R. G. et al. A pilot study of Anti-CTLA4 antibody ipilimumab in patients with synovial sarcoma. Sarcoma 2013, 1-8 (2013).

208. Broto, J. M. et al. IMMUNOSARC: a collaborative Spanish (GEIS) and Italian (ISG) sarcoma groups phase I/II trial of sunitinib plus nivolumab in advanced soft tissue and bone sarcomas: results of the phase II-soft-tissue sarcoma cohort. Ann. Oncol. 30, v684 (2019).

209. Jackson, H. J., Rafiq, S. \& Brentjens, R. J. Driving CAR T-cells forward. Nat. Rev. Clin. Oncol. 13, 370-383 (2016)

210. Wei, G., Ding, L., Wang, J., Hu, Y. \& Huang, H. Advances of CD19-directed chimeric antigen receptor-modified $\mathrm{T}$ cells in refractory/relapsed acute lymphoblastic leukemia. Exp. Hematol. Oncol. 6, 10 (2017).

211. Cao, J. et al. Potent anti-leukemia activities of humanized CD19-targeted Chimeric antigen receptor T (CAR-T) cells in patients with relapsed/refractory acute lymphoblastic leukemia. Am. J. Hematol. 93, 851-858 (2018).

212. Morello, A., Sadelain, M. \& Adusumilli, P. S. Mesothelin-targeted CARs: triving T cells to solid tumors. Cancer Discov. 6, 133-146 (2016).

213. Ahmed, N. et al. Human epidermal growth factor receptor 2 (HER2)-specific chimeric antigen receptor-modified T cells for the immunotherapy of HER2positive sarcoma. J. Clin. Oncol. 33, 1688-1696 (2015).

214. D'Angelo, S. P. et al. Pilot study of NY-ESO-1 c259 T cells in advanced myxoid/ round cell liposarcoma. J. Clin. Oncol. 36, 3005-3005 (2018).

215. Jungbluth, A. A. et al. Immunohistochemical analysis of NY-ESO-1 antigen expression in normal and malignant human tissues. Int. J. Cancer 92, 856-860 (2001).

216. Lai, J.-P. et al. NY-ESO-1 expression in synovial sarcoma and other mesenchymal tumors: significance for NY-ESO-1-based targeted therapy and differential diagnosis. Mod. Pathol. 25, 854-858 (2012).

217. D'Angelo, S. P. et al. Antitumor activity associated with prolonged persistence of adoptively transferred NY-ESO-1 c259 T cells in synovial sarcoma. Cancer Discov. 8, 944-957 (2018)

218. Thanindratarn, P., Dean, D. C., Nelson, S. D., Hornicek, F. J. \& Duan, Z. Chimeric antigen receptor $T$ (CAR-T) cell immunotherapy for sarcomas: from mechanisms to potential clinical applications. Cancer Treat. Rev. 82, 101934 (2020).

219. Knott, M. M. L. et al. Targeting the undruggable: exploiting neomorphic features of fusion oncoproteins in childhood sarcomas for innovative therapies. Cancer Metastasis Rev. 38, 625-642 (2019).

220. Bushweller, J. H. Targeting transcription factors in cancer-from undruggable to reality. Nat. Rev. Cancer 19, 611-624 (2019).

221. Blay, J.-Y. et al. Randomised phase III trial of trabectedin versus doxorubicinbased chemotherapy as first-line therapy in translocation-related sarcomas. Eur. J. Cancer 50, 1137-1147 (2014).

222. Kawai, A. et al. Trabectedin monotherapy after standard chemotherapy versus best supportive care in patients with advanced, translocation-related sarcoma: a randomised, open-label, phase 2 study. Lancet Oncol. 16, 406-416 (2015).

223. Forni, C. et al. Trabectedin (ET-743) promotes differentiation in myxoid liposarcoma tumors. Mol. Cancer Ther. 8, 449-457 (2009).

224. Pandey, P. R. et al. PAX3-FOXO1 is essential for tumour initiation and maintenance but not recurrence in a human myoblast model of rhabdomyosarcoma. J. Pathol. 241, 626-637 (2017).

225. Mitra, S. A., Ravinder, N., Magnon, V., Nagy, J. \& Triche, T. J. Abstract 4499: Genomic editing of EWS-FLI1 and its targets, and its therapeutic potential in treatment of Ewing sarcoma. In Molecular and Cellular Biology/Genetics 4499-4499 (American Association for Cancer Research, 2019).

226. Johnson, K. M. et al. Role for the EWS domain of EWS/FLI in binding GGAAmicrosatellites required for Ewing sarcoma anchorage independent growth. Proc. Natl Acad. Sci. USA 114, 9870-9875 (2017).

227. Riggi, N. et al. EWS-FLI1 utilizes divergent chromatin remodeling mechanisms to directly activate or repress enhancer elements in Ewing sarcoma. Cancer Cell 26, 668-681 (2014).

228. Boulay, G. et al. Epigenome editing of microsatellite repeats defines tumorspecific enhancer functions and dependencies. Genes Dev. 32, 1008-1019 (2018).

229. Martinez-Lage, M. et al. In vivo CRISPR/Cas9 targeting of fusion oncogenes for selective elimination of cancer cells. Nat. Commun. 11, 5060 (2020).

230. Tanaka, K., Iwakuma, T., Harimaya, K., Sato, H. \& Iwamoto, Y. EWS-Fli1 antisense oligodeoxynucleotide inhibits proliferation of human Ewing's sarcoma and primitive neuroectodermal tumor cells. J. Clin. Investig. 99, 239-247 (1997).

231. Hu-Lieskovan, S., Heidel, J. D., Bartlett, D. W., Davis, M. E. \& Triche, T. J. Sequencespecific knockdown of EWS-FLI1 by Targeted, Nonviral Delivery Of Small Interfering RNA inhibits tumor growth in a murine model of metastatic Ewing's sarcoma. Cancer Res. 65, 8984-8992 (2005)
232. Chansky, H. A. et al. Targeting of EWS/FLI-1 by RNA interference attenuates the tumor phenotype of Ewing's sarcoma cells in vitro. J. Orthop. Res. 22, 910-917 (2004).

233. Kikuchi, K. et al. Effects of PAX3-FKHR on malignant phenotypes in alveolar rhabdomyosarcoma. Biochem. Biophys. Res. Commun. 365, 568-574 (2008).

234. Bernasconi, M., Remppis, A., Fredericks, W. J., Rauscher, F. J. \& Schafer, B. W. Induction of apoptosis in rhabdomyosarcoma cells through down-regulation of PAX proteins. Proc. Natl Acad. Sci. USA 93, 13164-13169 (1996).

235. Carmody Soni, E. E., Schlottman, S., Erkizan, H. V., Uren, A. \& Toretsky, J. A. Loss of SS18-SSX1 inhibits viability and induces apoptosis in synovial sarcoma. Clin. Orthop. Relat. Res. 472, 874-882 (2014).

236. Cai, W. et al. The effect of SYT-SSX and extracellular signal-regulated kinase (ERK) on cell proliferation in synovial sarcoma. Pathol. Oncol. Res. 17, 357-367 (2011).

237. Laporte, A. N., Ji, J. X., Ma, L., Nielsen, T. O. \& Brodin, B. A. Identification of cytotoxic agents disrupting synovial sarcoma oncoprotein interactions by proximity ligation assay. Oncotarget 7, 34384-34394 (2016).

238. Ma, Y. et al. Targeted inhibition of histone deacetylase leads to suppression of Ewing sarcoma tumor growth through an unappreciated EWS-FLI1/HDAC3/ HSP90 signaling axis. J. Mol. Med. 97, 957-972 (2019).

239. Thalhammer, V. et al. PLK1 phosphorylates PAX3-FOXO1, the inhibition of which triggers regression of alveolar rhabdomyosarcoma. Cancer Res. 75, 98-110 (2015).

240. Abbou, S. et al. Polo-like kinase inhibitor volasertib exhibits antitumor activity and synergy with vincristine in pediatric malignancies. Anticancer Res. 36, 599-609 (2016).

241. Bid, H. K. et al. The bromodomain BET inhibitor JQ1 suppresses tumor angiogenesis in models of childhood sarcoma. Mol. Cancer Ther. 15, 1018-1028 (2016).

242. Tirado, O. M. Targeting fusion proteins: a double edge sword? Expert Opin. Ther Targets 23, 651-654 (2019).

243. Soucek, L. et al. Omomyc, a potential Myc dominant negative, enhances Mycinduced apoptosis. Cancer Res. 62, 3507-3510 (2002).

244. Beaulieu, M.-E. et al. Intrinsic cell-penetrating activity propels Omomyc from proof of concept to viable anti-MYC therapy. Sci. Transl. Med. 11, eaar5012 (2019).

245. Delmore, J. E. et al. BET bromodomain inhibition as a therapeutic strategy to target c-Myc. Cell 146, 904-917 (2011).

246. Filippakopoulos, P. et al. Selective inhibition of BET bromodomains. Nature $\mathbf{4 6 8}$, 1067-1073 (2010)

247. Zuber, J. et al. RNAi screen identifies Brd4 as a therapeutic target in acute myeloid leukaemia. Nature 478, 524-528 (2011).

248. Mertz, J. A. et al. Targeting MYC dependence in cancer by inhibiting BET bromodomains. Proc. Natl Acad. Sci. USA 108, 16669-16674 (2011).

249. Gollavilli, P. N. et al. EWS/ETS-driven Ewing sarcoma requires BET bromodomain proteins. Cancer Res. 78, 4760-4773 (2018).

250. Sakamoto, K. M. et al. Protacs: chimeric molecules that target proteins to the Skp1-Cullin-F box complex for ubiquitination and degradation. Proc. Natl Acad. Sci. USA 98, 8554-8559 (2001).

251. Lu, J. et al. Hijacking the E3 ubiquitin ligase cereblon to efficiently target BRD4. Chem. Biol. 22, 755-763 (2015).

252. Lu, Q. et al. BRD4 degrader ARV-825 produces long-lasting loss of BRD4 protein and exhibits potent efficacy against cholangiocarcinoma cells. Am. J. Transl. Res. 11, 5728-5739 (2019).

253. Cooper, J. M. et al. Overcoming BET inhibitor resistance in malignant peripheral nerve sheath tumors. Clin. Cancer Res. 25, 3404-3416 (2019).

254. Shi, C. et al. PROTAC induced-BET protein degradation exhibits potent antiosteosarcoma activity by triggering apoptosis. Cell Death Dis. 10, 815 (2019).

255. Li, Y. et al. Discovery of MD-224 as a first-in-class, highly potent, and efficacious proteolysis targeting chimera murine double minute 2 degrader capable of achieving complete and durable tumor regression. J. Med. Chem. 62, 448-466 (2019).

256. Colella, G. et al. Sarcoma spheroids and organoids-promising tools in the era of personalized medicine. Int. J. Mol. Sci. 19, 615 (2018).

257. Blomme, A. et al. Murine stroma adopts a human-like metabolic phenotype in the PDX model of colorectal cancer and liver metastases. Oncogene 37, 1237-1250 (2018)

258. Hidalgo, M. et al. Patient-derived xenograft models: an emerging platform for translational cancer research. Cancer Discov. 4, 998-1013 (2014).

259. Kresse, S. H., Meza-Zepeda, L. A., Machado, I., Llombart-Bosch, A. \& Myklebost, O. Preclinical xenograft models of human sarcoma show nonrandom loss of aberrations. Cancer 118, 558-570 (2012).

260. Imle, R., Kommoss, F. K. F. \& Banito, A. Preclinical in vivo modeling of pediatric sarcoma-promises and limitations. J. Clin. Med. 10, 1578 (2021). 
261. Dong, $X$. et al. Patient-derived first generation xenografts of non-small cell lung cancers: promising tools for predicting drug responses for personalized chemotherapy. Clin. Cancer Res. 16, 1442-1451 (2010).

262. Bertotti, A. et al. A molecularly annotated platform of patient-derived xenografts ('Xenopatients') identifies HER2 as an effective therapeutic target in cetuximabresistant colorectal cancer. Cancer Discov. 1, 508-523 (2011).

263. Julien, S. et al. Characterization of a large panel of patient-derived tumor xenografts representing the clinical heterogeneity of human colorectal cancer. Clin. Cancer Res. 18, 5314-5328 (2012).

264. DeRose, Y. S. et al. Tumor grafts derived from women with breast cancer authentically reflect tumor pathology, growth, metastasis and disease outcomes. Nat. Med. 17, 1514-1520 (2011).

265. Garrido-Laguna, I. et al. Tumor engraftment in nude mice and enrichment in stroma- related gene pathways predict poor survival and resistance to gemcitabine in patients with pancreatic cancer. Clin. Cancer Res. 17, 5793-5800 (2011).

266. Nanni, P. et al. Bone sarcoma patient-derived xenografts are faithful and stable preclinical models for molecular and therapeutic investigations. Sci. Rep. 9, 12174 (2019).

267. Rainusso, N. et al. Generation of patient-derived tumor xenografts from percutaneous tumor biopsies in children with bone sarcomas. Pediatr. Blood Cancer e27579 (2018). https://doi.org/10.1002/pbc.27579.

268. Stewart, E. et al. Orthotopic patient-derived xenografts of paediatric solid tumours. Nature 549, 96-100 (2017).

269. Meohas, W. et al. Patient-derived xenografts as a preclinical model for bone sarcomas. Acta Ortop. Bras. 26, 98-102 (2018).

270. Cornillie, J. et al. Establishment and characterization of histologically and molecularly stable soft-tissue sarcoma xenograft models for biological studies and preclinical drug testing. Mol. Cancer Ther. 18, 1168-1178 (2019).

271. Barham, W. et al. Targeting the Wnt pathway in synovial sarcoma models. Cancer Discov. 3, 1286-1301 (2013).

272. Zhao, S. et al. NKD2, a negative regulator of Wnt signaling, suppresses tumor growth and metastasis in osteosarcoma. Oncogene 34, 5069-5079 (2015).

273. Li, Z. et al. miR-130b targets NKD2 and regulates the Wnt signaling to promote proliferation and inhibit apoptosis in osteosarcoma cells. Biochem. Biophys. Res. Commun. 471, 479-485 (2016).

274. Tanaka, M. et al. Ewing's sarcoma precursors are highly enriched in embryonic osteochondrogenic progenitors. J. Clin. Investig. 124, 3061-3074 (2014).

275. Rahrmann, E. P. et al. Forward genetic screen for malignant peripheral nerve sheath tumor formation identifies new genes and pathways driving tumorigenesis. Nat. Genet. 45, 756-766 (2013).

276. Luscan, A. et al. The activation of the WNT signaling pathway is a hallmark in neurofibromatosis Type 1 tumorigenesis. Clin. Cancer Res. 20, 358-371 (2014).

277. Watson, A. L. et al. Canonical Wnt/ $\beta$-catenin signaling drives human Schwann cell transformation, progression, and tumor maintenance. Cancer Discov. 3, 674-689 (2013).

278. Kephart, J. J. G. et al. Secreted frizzled-related protein 3 (SFRP3) is required for tumorigenesis of PAX3-FOXO1-positive alveolar rhabdomyosarcoma. Clin. Cancer Res. 21, 4868-4880 (2015).

279. Rota, R., Ciarapica, R., Miele, L. \& Locatelli, F. Notch signaling in pediatric soft tissue sarcomas. BMC Med. 10, 141 (2012).

280. Wang, C. Y. Y. et al. Hedgehog and notch signaling regulate self-renewal of undifferentiated pleomorphic sarcomas. Cancer Res. 72, 1013-1022 (2012).

281. Tokuyama, W., Mikami, T., Masuzawa, M. \& Okayasu, I. Autocrine and paracrine roles of VEGF/VEGFR-2 and VEGF-C/NEGFR-3 signaling in angiosarcomas of the scalp and face. Hum. Pathol. 41, 407-414 (2010).

282. Olmos, D. et al. Targeting the insulin-like growth factor 1 receptor in Ewing's sarcoma: reality and expectations. Sarcoma 2011, 1-13 (2011).

283. Wan, X. \& Helman, L. J. Levels of PTEN protein modulate Akt phosphorylation on serine 473 , but not on threonine 308 , in IGF-II-overexpressing rhabdomyosarcomas cells. Oncogene 22, 8205-8211 (2003).

284. Holtkamp, N. et al. Mutation and expression of PDGFRA and KIT in malignant peripheral nerve sheath tumors, and its implications for imatinib sensitivity. Carcinogenesis 27, 664-671 (2006).

285. Yang, Z. et al. Knockdown of YAP1 inhibits the proliferation of osteosarcoma cells in vitro and in vivo. Oncol. Rep. 32, 1265-1272 (2014).

286. Hsu, J. H. \& Lawlor, E. R. BMI-1 suppresses contact inhibition and stabilizes YAP in Ewing sarcoma. Oncogene 30, 2077-2085 (2011).

287. Avigad, S. et al. Aberrant methylation and reduced expression of RASSF1A in Ewing sarcoma. Pediatr. Blood Cancer 53, 1023-1028 (2009).

288. Tremblay, A. M. et al. The Hippo transducer YAP1 transforms activated satellite cells and is a potent effector of embryonal rhabdomyosarcoma formation. Cancer Cell 26, 273-287 (2014).

289. Crose, L. E. S. et al. Alveolar rhabdomyosarcoma-associated PAX3-FOXO1 promotes tumorigenesis via Hippo pathway suppression. J. Clin. Invest. 124, 285-296 (2014).
290. Gamberi, G. et al. Molecular diagnosis in Ewing Family tumors. J. Mol. Diagnostics 13, 313-324 (2011).

291. Antonescu, C. R. et al. Molecular diagnosis of clear cell sarcoma. J. Mol. Diagnostics 4, 44-52 (2002).

292. Mitelman, F. Catalog of Chromosome Aberrations in Cancer (Wiley-Liss, Inc., 1994).

293. Antonescu, C. R. et al. Prognostic impact of P53 status, TLS-CHOP fusion transcript structure, and histological grade in myxoid liposarcoma: a molecular and clinicopathologic study of 82 cases. Clin. Cancer Res. 7, 3977-3987 (2001).

294. Panagopoulos, I. et al. Characterization of the CHOP breakpoints and fusion transcripts in myxoid liposarcomas with the 12;16 translocation. Cancer Res. 54, 6500-6503 (1994).

295. Panagopoulos, I. et al. Fusion of the EWS and CHOP genes in myxoid liposarcoma. Oncogene 12, 489-494 (1996).

296. Dal Cin, P. et al. Additional evidence of a variant translocation $t(12 ; 22)$ withEWS/ CHOP fusion in myxoid liposarcoma: clinicopathological features. J. Pathol. 182, 437-441 (1997).

297. Agaram, N. P., Zhang, L., Sung, Y.-S., Singer, S. \& Antonescu, C. R. Extraskeletal myxoid chondrosarcoma with non-EWSR1-NR4A3 variant fusions correlate with rhabdoid phenotype and high-grade morphology. Hum. Pathol. 45, 1084-1091 (2014).

298. Noujaim, J. et al. The spectrum of EWSR1-rearranged neoplasms at a tertiary sarcoma centre; assessing 772 tumour specimens and the value of current ancillary molecular diagnostic modalities. Br. J. Cancer 116, 669-678 (2017).

299. Mohamed, M. et al. Desmoplastic small round cell tumor: evaluation of reverse transcription-polymerase chain reaction and fluorescence in situ hybridization as ancillary molecular diagnostic techniques. Virchows Arch. 471, 631-640 (2017).

300. Sorensen, P. H. B. et al. PAX3-FKHR and PAX7-FKHR Gene Fusions Are Prognostic Indicators in Alveolar Rhabdomyosarcoma: A Report From the Children's Oncology Group. J. Clin. Oncol. 20, 2672-2679 (2002).

301. Sumegi, J. et al. Recurrent $t(2 ; 2)$ and $t(2 ; 8)$ translocations in rhabdomyosarcoma without the canonical PAX-FOXO1 fuse PAX3 to members of the nuclear receptor transcriptional coactivator family. Genes Chromosom. Cancer https:// doi.org/10.1002/gcc.20731 (2009).

302. Wachtel, M. et al. Gene expression signatures identify rhabdomyosarcoma subtypes and detect a novel $t(2 ; 2)(q 35 ; p 23)$ translocation fusing PAX3 to NCOA1. Cancer Res. 64, 5539-5545 (2004).

303. Tsuji, K., Ishikawa, Y. \& Imamura, T. Technique for differentiating alveolar soft part sarcoma from other tumors in paraffin-embedded tissue: comparison of immunohistochemistry for TFE3 and CD147 and of reverse transcription polymerase chain reaction for ASPSCR1-TFE3 fusion transcript. Hum. Pathol. 43, 356-363 (2012).

304. Aulmann, S., Longerich, T., Schirmacher, P., Mechtersheimer, G. \& Penzel, R. Detection of the ASPSCR1-TFE3 gene fusion in paraffin-embedded alveolar soft part sarcomas. Histopathology 50, 881-886 (2007).

305. Kawai, A. et al. SYT-SSX gene fusion as a determinant of morphology and prognosis in synovial sarcoma. N. Engl. J. Med. 338, 153-160 (1998).

306. Ladanyi, M. et al. Impact of SYT-SSX fusion type on the clinical behavior of synovial sarcoma: a multi-institutional retrospective study of 243 patients. Cancer Res. 62, 135-140 (2002).

307. Skytting, B. et al. A novel fusion gene, SYT-SSX4, in synovial sarcoma.JNCI J. Natl Cancer Inst. 91, 974-975 (1999).

308. Orbach, D. et al. Conservative strategy in infantile fibrosarcoma is possible: the European paediatric Soft tissue sarcoma Study Group experience. Eur. J. Cancer 57, 1-9 (2016).

309. Knezevich, S. R., McFadden, D. E., Tao, W., Lim, J. F. \& Sorensen, P. H. B. A novel ETV6-NTRK3 gene fusion in congenital fibrosarcoma. Nat. Genet. 18, 184-187 (1998).

310. Bourgeois, J. M., Knezevich, S. R., Mathers, J. A. \& Sorensen, P. H. B. Molecular detection of the ETV6-NTRK3 gene fusion differentiates congenital fibrosarcoma from other childhood spindle cell tumors. Am. J. Surg. Pathol. 24, 937-946 (2000).

311. El-Rifai, W., Sarlomo-Rikala, M., Knuutila, S. \& Miettinen, M. DNA copy number changes in development and progression in leiomyosarcomas of soft tissues. Am. J. Pathol. 153, 985-990 (1998).

312. Chudasama, P. et al. Integrative genomic and transcriptomic analysis of leiomyosarcoma. Nat. Commun. 9, 144 (2018).

313. Yang, C. Y. et al. Targeted next-generation sequencing of cancer genes identified frequent TP53 and ATRX mutations in leiomyosarcoma. Am. J. Transl. Res. 7, 2072-2081 (2015).

314. Mäkinen, N. et al. Exome sequencing of uterine leiomyosarcomas identifies frequent mutations in TP53, ATRX, and MED12. PLoS Genet. 12, e1005850 (2016). 
Molecular mechanisms underpinning sarcomas and implications for current... Damerell et al.

315. Perot, G. et al. Strong smooth muscle differentiation is dependent on myocardin gene amplification in most human retroperitoneal leiomyosarcomas. Cancer Res. 69, 2269-2278 (2009).

316. Chen, $X$. et al. Recurrent somatic structural variations contribute to tumorigenesis in pediatric osteosarcoma. Cell Rep. 7, 104-112 (2014).

317. Kovac, M. et al. Exome sequencing of osteosarcoma reveals mutation signatures reminiscent of BRCA deficiency. Nat. Commun. 6, 8940 (2015).

318. Sayles, L. C. et al. Genome-informed targeted therapy for osteosarcoma. Cancer Discov. 9, 46-63 (2019).

319. Won, K. Y., Park, H.-R. \& Park, Y.-K. Prognostic implication of immunohistochemical Runx2 expression in osteosarcoma. Tumori 95, 311-316 (2009).

320. Gupta, S. et al. RUNX2 (6p21.1) amplification in osteosarcoma. Hum. Pathol. 94, 23-28 (2019).

321. Hostein, I. et al. Evaluation of MDM2 and CDK4 amplification by real-time PCR on paraffin wax-embedded metarial: a potential tool for the diagnosis of atypical lipomatous tomours/well-defferentiated liposarcomas. J. Pathol. 202, 95-102 (2004)

322. Saâda-Bouzid, E. et al. Prognostic value of HMGA2, CDK4, and JUN amplification in welldifferentiated and dedifferentiated liposarcomas. Mod. Pathol. 28, 1404-1414 (2015).

323. Amary, M. F. et al. IDH1 and IDH2 mutations are frequent events in central chondrosarcoma and central and periosteal chondromas but not in other mesenchymal tumours. J. Pathol. 224, 334-343 (2011).

324. Cojocaru, E., Wilding, C., Engelman, B., Huang, P. \& Jones, R. L. Is the IDH mutation a good target for chondrosarcoma treatment? Curr. Mol. Biol. Rep. 6, 1-9 (2020).

325. Schmidt, $H$. et al. Gains of $12 q$ are the most frequent genomic imbalances in adult fibrosarcoma and are correlated with a poor outcome. Genes Chromosom. Cancer 34, 69-77 (2002).

326. Paulson, V. et al. High-resolution array CGH identifies common mechanisms that drive embryonal rhabdomyosarcoma pathogenesis. Genes Chromosom. Cancer 50, 397-408 (2011).
327. Zietz, C. et al. MDM-2 oncoprotein overexpression, p53 gene mutation, and VEGF up-regulation in angiosarcomas. Am. J. Pathol. 153, 1425-1433 (1998).

328. Brohl, A. S., Kahen, E., Yoder, S. J., Teer, J. K. \& Reed, D. R. The genomic landscape of malignant peripheral nerve sheath tumors: diverse drivers of Ras pathway activation. Sci. Rep. 7, 14992 (2017).

329. Lee, W. et al. PRC2 is recurrently inactivated through EED or SUZ12 loss in malignant peripheral nerve sheath tumors. Nat. Genet. 46, 1227-1232 (2014).

330. Chibon, F. et al. The RB1 gene is the target of chromosome 13 deletions in malignant fibrous histiocytoma. Cancer Res. 60, 6339-6345 (2000).

331. Mertens, F. et al. Cytogenetic analysis of 46 pleomorphic soft tissue sarcomas and correlation with morphologic and clinical features: a report of the CHAMP study group. Genes Chromosom. Cancer 22, 16-25 (1998).

Open Access This article is licensed under a Creative Commons Attribution 4.0 International License, which permits use, sharing, adaptation, distribution and reproduction in any medium or format, as long as you give appropriate credit to the original author(s) and the source, provide a link to the Creative Commons license, and indicate if changes were made. The images or other third party material in this article are included in the article's Creative Commons license, unless indicated otherwise in a credit line to the material. If material is not included in the article's Creative Commons license and your intended use is not permitted by statutory regulation or exceeds the permitted use, you will need to obtain permission directly from the copyright holder. To view a copy of this license, visit http://creativecommons. org/licenses/by/4.0/.

(c) The Author(s) 2021 